\title{
CHAFARINAS DURANTE EL SIGLO XX
}

CARLOS ESQUEMBRI HINOJO

Asociación de Estudios Melillenses

\section{LA VUELTA DE SATURNINO JIMÉNEZY EL CONTRABANDO DE ARMAS}

Aunque el fin del siglo XIX significó para Chafar inas, como para el resto del país, un tiempo de crisis, llegándose, incluso, a hablar de venderlas a Alemania junto con las Carolinas, la llegada del siglo XX abrió nuevas expectativas para las islas.

\section{El nuevo proyecto de Saturnino Jiménez para Chafarinas 1902}

Ante el fracaso de su proyecto de factoría comercial en la costa de Quebdana, Jiménez vendió esos terreros en 1885 a una sociedad barcelonesa llamada Compañía Comercial Hispano-Africana. Esta compañía intentó que el gobier no español estableciera un protectorado sobre el territorio en que estaban situados sus terrenos como garantía antes de estab lecer la proyectada factoría, pero la negativa del gobierno a realizar esta acción, hizo que el proyecto quedara momentáneamente en el olvido ${ }^{1}$.

No es hasta septiembre de 1901, con la vuelta de Jiménez a Melilla,cuando el proyecto de factoría comercial en Chałrinas cobra nuevo impulso. Jiménez se estableció en Melilla acompañado de su esposa, una mujer rusa de la que se decía era hija del ingeniero que construyó la base naval rusa de Port Arthur, en Corea. Se ganó la confianza del Comandante General,Venancio Hernández, que llegó a enviar telegramas al GeneralWeyler, Ministro de la Guerra, recomendando el proyecto de factoría en Chafarinas ${ }^{2}$.

El establecimiento que Jiménez pensaba instalar en la isla del Rø consistiría en un depósito de carbón,almacenes, varadero y talleres de reparación. Esta-

1 España y la apertura de la cuestión marroquí págs. 334 y ss.

2 Telegramas citados en España, Alemania y Chafarinas. 
ría conectado por correo con Cabo del Agua y el resto de Marruecos y serviría de punto de r ecepción y distribución de mercancías para toda la costa nor te marroquí. Jiménez llegó a fundar una compañía mercantil denominada'Sindicato Español del Norte de África” con sede en las Chafrinas y conexiones en Orán y con casas comerciales españolas. Para que esta empresa prosperase era necesario abrir al comercio toda la costa mar roquí, por lo que Jiménez planeó una campaña de prensa defendiendo esta liberalización del comercio ${ }^{3}$. Finalmente el proyecto fracasó, entre otros motivos por ser poco viable dada las posibilidades reales de las islas ${ }^{4}$.

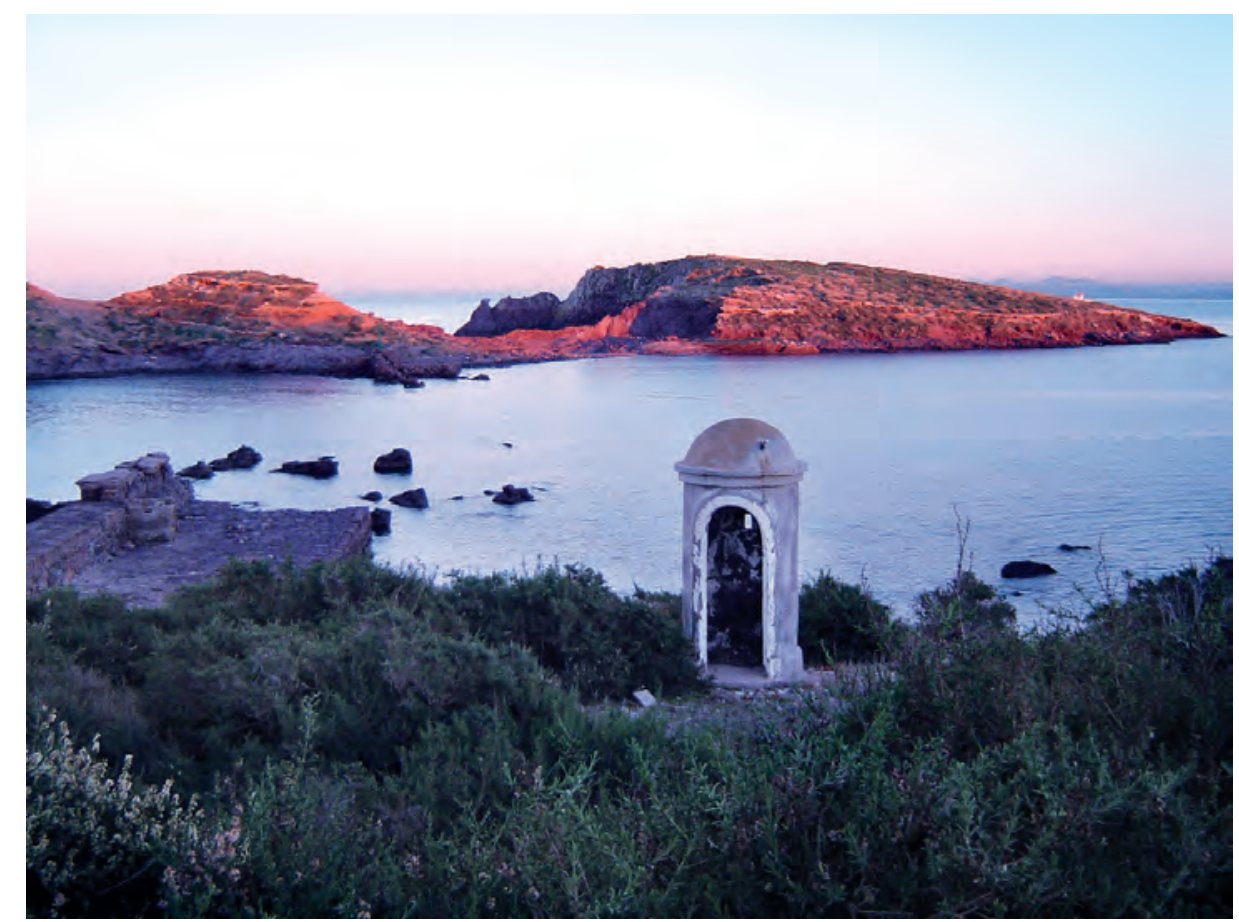

Isla del Rey al fondo, donde Saturnino Jiménez proyectaba instalar un depósito de carbón, almacenes, varadero y talleres de reparación.

Este asunto no hubiera pasado de considerarse un mero fracaso empresarial de no ser por una carta publicada en septiembre de 1902 en el diario de París

3 España, Alemania y Chafarinas.

4 El Liberal 23/09/1902. 
Le Siecle y recogida por toda la prensa nacional. Esta carta estaba escrita por Leon Dubochef, un francés residente en Kiss, y describe una visita a Chafarinas donde fue recibido por Saturnino Jiménez, que se presentaba como propietario de la isla del Rey en virtud de una Real Orden de 5 de agosto de 1902 por la que se le había otorgado la concesión de dic ha isla para establecer una factoría. Jiménez presumía también de una gran amistad con el general Weyler, llegando a asegurar que, por sugerencia suya, se iba a sustituir al gobemador de Chafarinas, coronel Pablo Artal y Abad, por un joven capitán de artillería llamado Rafael Ripoll y Cabrera destinado en Melilla y que, según Jiménez, era más par tidario de sus proyectos que Artal ${ }^{5}$.

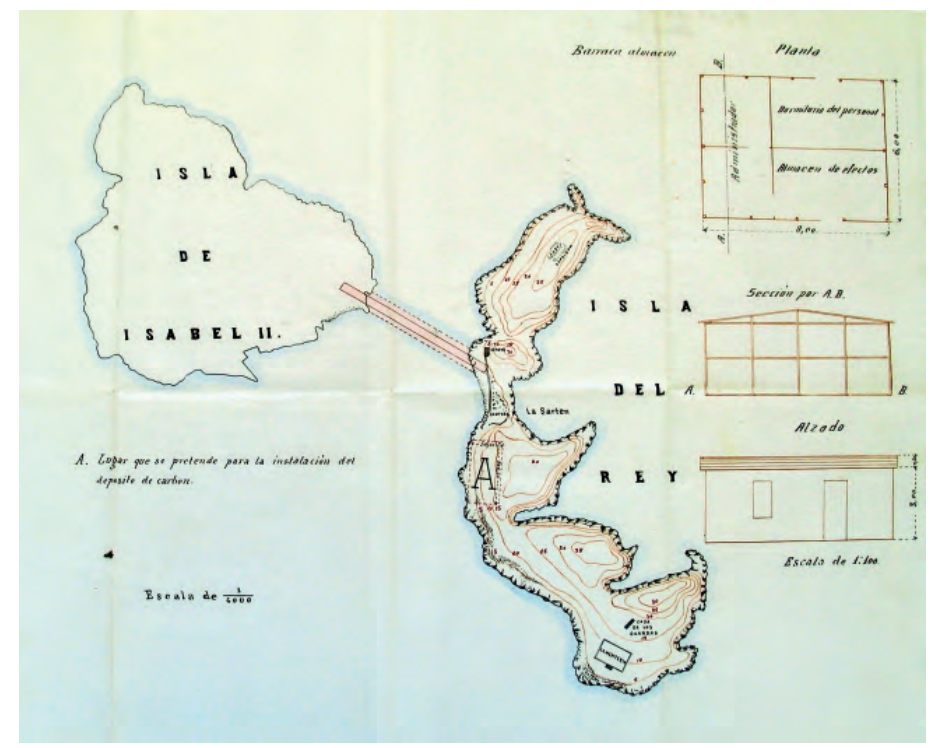

Proyecto para depósito de carbón en las islas Chafarinas. Fechado en 1907, Archivo General de Segovia.

El contenido de la car ta generó un cier to escándalo mediático en unos momentos en que la cuestión afr icanista cobraba nue vos auges y el gobier no tuvo que desmentir el que se hubiera otorgado una concesión a Jiménez.

Este asunto de Chafarinas llegó incluso hasta el parlamento br itánico. $\mathrm{La}$ Correspondencia Militar del cinco de diciembre de 1902 se hacía eco de la pegun-

5 El Día, El País y La Correspondencia de España del 20/09/1902. La Dinastía 23/04/1902. 
ta de un parlamentario al gobierno en la Cámara de los Comunes sobre la veracidad de los rumores que corrían acerca de la cesión de las Chafirinas a Rusia, no olvidemos la nacionalidad de la esposa de Jiménez.

\section{El contrabando de armas y sus implicaciones}

Las armas y municiones eran uno de los productos más demandados por los contrabandistas marroquíes y con la llegada al valle del Muluya del pretendiente al trono marroquí conocido como El Roghi, en 1902, esta demanda se incrementó. El auge de este tráfico dio un poder económico a los traficantes de armas y sus cómplices que llegó a amenazar el tradicional dominio que los gobernadores militares habían mantenido sobre la población isleña. En la prensa militar se llegó a hablar de "caciquismo" ejercido por este grupo de comerciantes que podían arruinar la carrera profesional de los gobernadores que se opusieran a sus manejos ${ }^{6}$. Es posible que este "caciquismo" del que hablaba la prensa militar fuera simplemente el deseo de los civiles de par ticipar en el gobier no de su pequeña población, ejercido desde la Junta deArbitrios, un organismo creado en 1897 que estaba presidido por el gobernador militar y compuesto únicamente por militares hasta 1902.

El asunto del contrabando de ar mas saltó a la opinión púb lica con una carta (que aparecía firmada con el seudónimo de Mustafá) y fehada en Melilla el 6 de noviembre de 1902 que fue pub licada en el per iódico El Día del 10 de noviembre. En ella se relataba que una noche de primeros de octubre, una barca salió sin permiso de las islas con rumbo a la costa marroquí. Esa misma noche se descubrió que habían roto una ventana del parque de artillería y que faltaban dos fusiles Remintong de los almacenados allí. A la mañana siguiente volvió la barca y se procedió a detener a sus tripulantes, incautándose al patrón setenta duros que se supuso procedían de la venta de los fusiles, cosa que negaba el imputado. Aunque se abrió una investigación oficial, poco se aclaró del asunto. Sin embargo, tanto el periódico El Día como La Correspondencia Militar publicaron una serie de artículos donde se desvelaban parte de los entresijos de este tráfico ilícito.

El contrabando se centraba en fusiles Remintong y en m uniciones. Estos fusiles eran conocidos por los marroquíes como "Mericanos" por su origen, aunque los que compraban eran españoles o belgas. Se utilizaba la isla deshabitada

6 La Correspondencia Militar 24/02/1903. 
del Congreso, para ocultar los cargamentos hasta su enta a los marroquíes. En la prensa se mencionaban algunos nombres y alias de estos traficantes marroquíes como "Curro", "Tiñoso", "Hamete el Negro" o "Chorlito" cuyo nombre real era ÄHamudÄKailul de los Uled - el- Hadj,Äy que fue el pr incipal traficante de la zona. Éste había organizado una banda con sus $f$ amiliares que se dedicaban al contrabando desde Chafarinas y al robo de ganado en Quebdana y Kiss Parte del ganado robado se vendía en Chafarinas introduciéndolo de noche en las islas. El final de "Chorlito" llegó cuando quiso ampliar sus actividades delictias a la organización de fugas de presidiarios. Durante una de estas fugas murió en un enfrentamiento con los centinelas de Isabel II el 9 de diciembre de $1901^{7}$.

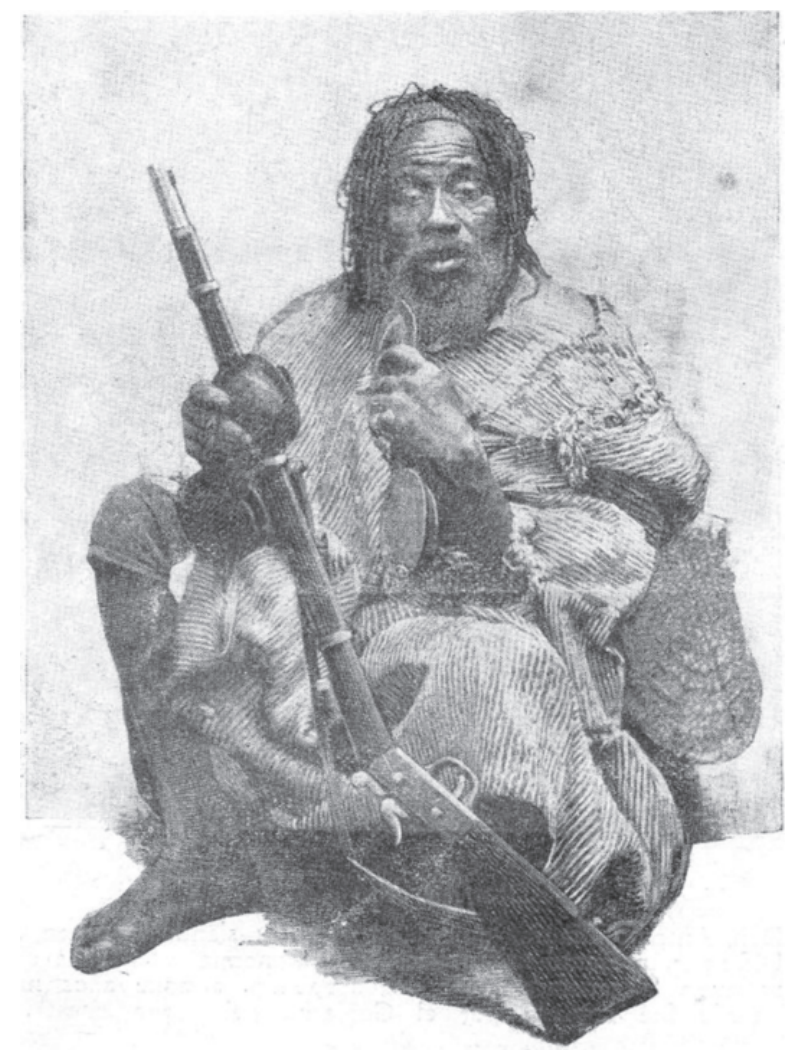

Guerrero rifeño. La Ilustración Española y Americana.

7 La Correspondencia Militar 11/02/1903; 12/02/1903; 24/02/1903. El Día 11/02/1903; 13/ $02 / 1903$. 


\section{CHAFARINASY EL PRINCIPIO DE LAACCIÓN ESPAÑOLA EN MARRUECOS.}

En los primeros años del siglo XX el gobiemo español fue tomando determinaciones de cara al desarrollo de las islas en consonancia con el enovado interés que España experimentaba hacia la llamada penetración en Marruecos.

Una de ellas fue la construcción del puerto de Chafarinas. Las obras que se iniciaron en 1906 significaron un revulsivo económico para las islas debido a las inversiones y al aumento de pob lación que originaron. Por los mismos años se experimentó un aumento del comercio con Quebdana tras su ocupación por las tropas del Roghi Bu Hamara,pretendiente al trono de Marruecos. Los cárabos visitaban libremente las islas para comprar y se llegó, incluso, a comerciar a la v ez con las tropas de la Mehala Imper ial que quedaban en la zona. En la recopilación de datos económicos sobre los presidios menores de 1908, recogidos por el historiador Gabriel de Morales, encontramos que Chafarinas exportó esparto, carbón y cebada por un valor de 2.232 pesetas e importó tejidos, té, harinas, jabón, café, azúcar y sal entre otros artículos por un valor de 489.318,50 pesetas, mercancías que en su mayor parte se venderían a comerciantes de Quebdana. Este comercio se mantuvo varios años y en la información portuaria de Cartagena, por ejemplo, encontramos que en marzo de 1921 llegó a aquel puerto un laúd llamado Ángeles con un cargamento de carbón desde Chafarinas ${ }^{8}$.

Sin embargo, estas buenas expecta tivas para el desar rollo no fuer on muy sólidas ni duraderas y en poco tiempo se esfumaron ante el devenir de los acontecimientos. Incluso la impor tancia de Chafar inas como puerto de refugio se vio relativizada con la ocupación de toda la península del cabo Tres Forcas durante la guerra de 1909, ya que posibilitó que los b uques buscaran resguardo en la cara oeste del cabo en caso de malos tiempos de levante con la posibilidad de comunicarse por tierra con Melilla. De ahí que ya ni se reparara el dique que unía las islas de Isabel II y del Rey tras su rotura durante el temporal de marzo de 1914.

La ocupación de Cabo del Agua, que fue encabezada por la compañía de infantería de ser vicio en Chafarinas mandada por el comandante militar de las islas, el teniente coronel Eugenio Anca, también afectó negativamente a las islas

$8 \quad$ La Tierra 09/03/1921. 
ya que desvió algunos negocios al poblado que se construyó junto al puesto militar. Esta acción, según justificó el gobierno español, se llevó a cabo a instancias de los notables de Quebdana como ayuda a la defensa y custodia de un almacén de víveres que habían aceptado instalar en Cabo delAgua con destino al suministro de la crecida población de Chafarinas debido al elevado número de obreros contratados para las obras del puerto.

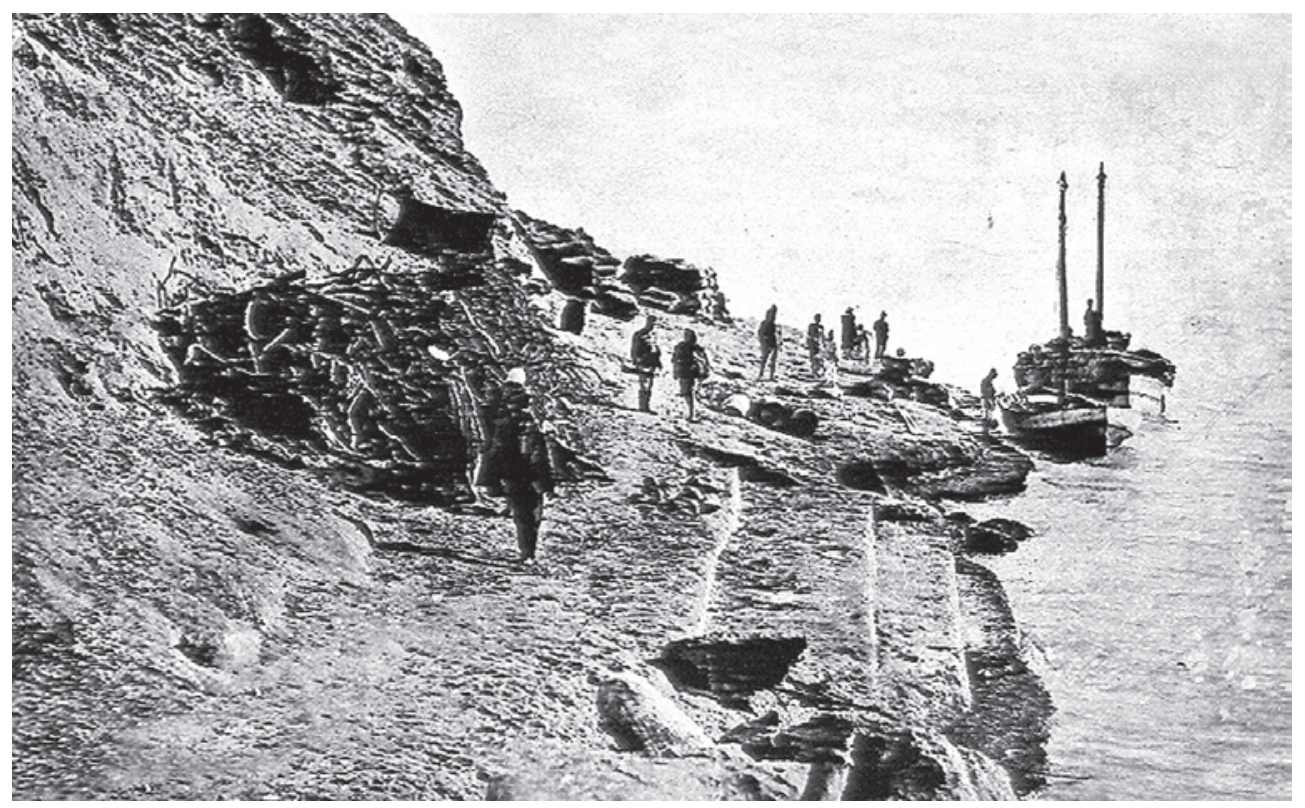

Desembarcadero de Cabo del Agua a principios del siglo XX.

\section{La guerra de 1909}

El principal papel de Chafar inas durante el conflicto fue el de ser vir de puerto de refugio de los buques que arribaban a Melilla con refuerzos y pertrechos en caso de soplar temporal de levante. Igual cometido tuvo durante el asedio de 1774 - 1775 y durante la llamada Campaña de Margallo de 1894, con la salvedad de que en 1909 también se utilizaon las islas como estación de carboneo para los buques de la Armada. Ya con la llegada de los primeros refuerzos el día 13 de julio en el "Montevideo" de la Trasatlántica y al encontrarse el puerto de Melilla cerrado por temporal de le vante, tuvo el buque que buscar refugio en Chafarinas. Lo mismo se vio obligado a hacer el "Buenos Aires” que arribó el 14. 
No es hasta el 15 por la mañana que se pudo iniciar el desembarco de las opas. Así fue ocurriendo a lo largo de la campaña cada vez que el levante hacía su aparición con fuerza, como ocurrió a finales de octubre cuando el temporal rugió tantos días que la guarnición tuvo que socorrer con alimentos a las tripulaciones de los buques fondeados al resguardo de las islas ${ }^{9}$. También se utilizó el hospital de Chafarinas para descongestionar el de Melilla de enfermos y heridos convalecientes.

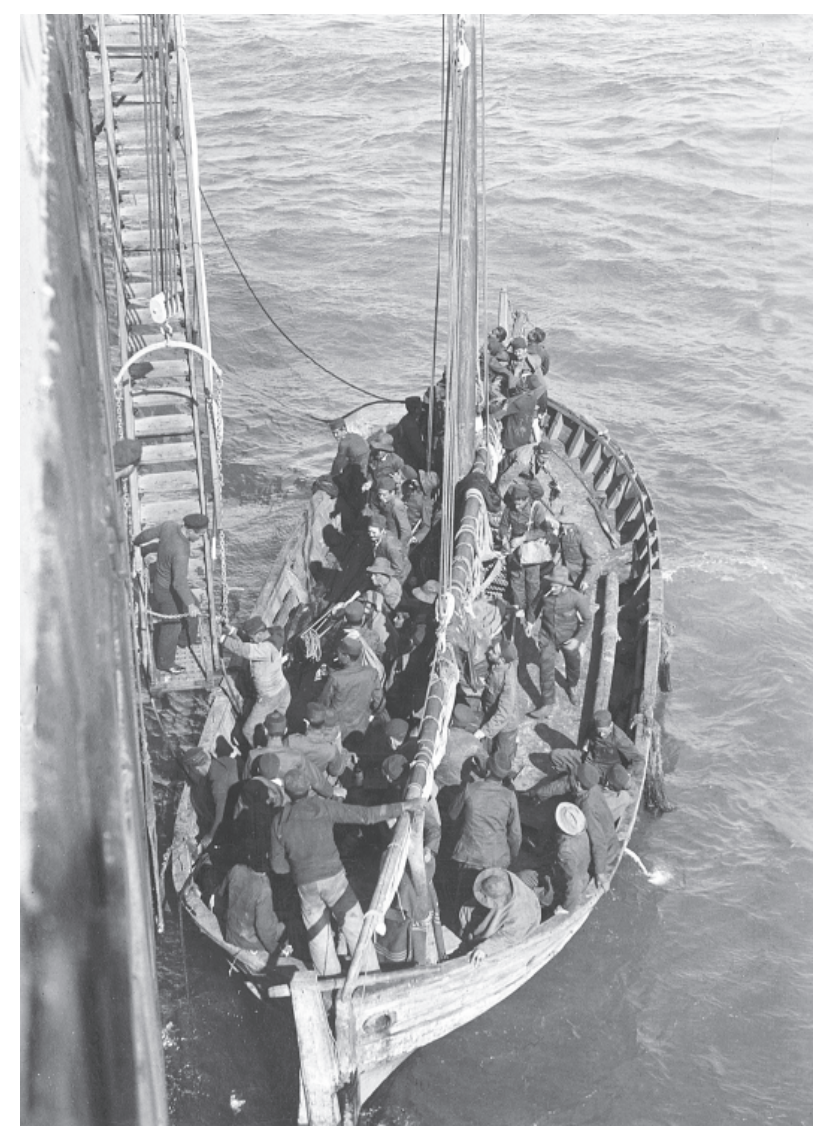

Soldados bajando a los botes para proceder al desembarco a puerto. Fotografía EFE.

Este papel secundario de Chafarinas estuvo también motivado porque las cabilas de Quebdana no se unieron a la harka de Guelaya y el territorio próximo 
a las islas se mantuvo prácticamente pacífico en todo el conflicto. La ocupación efectiva del mismo se realizó en septiembre desde el campamento de Cabo del Agua por una columna al mando del cor onel Larrea. Una de las pocas bajas sufridas en esta zona, el soldado Francisco Nebot, muerto en Cabo del Agua de las heridas sufridas en combate, fue enterrado en el cementerio de Chafarinas. El cadáver se llevó hasta la isla de Isabel II por el vapor Sirena, fletado por el diario La Correspondencia de España, y el cadáver fue conducido al cementer io por los periodistas, Armiñán, Leopoldo Romeo (dir ector del diar io), Guillermo Rittwagen y Ferrer. ${ }^{10}$

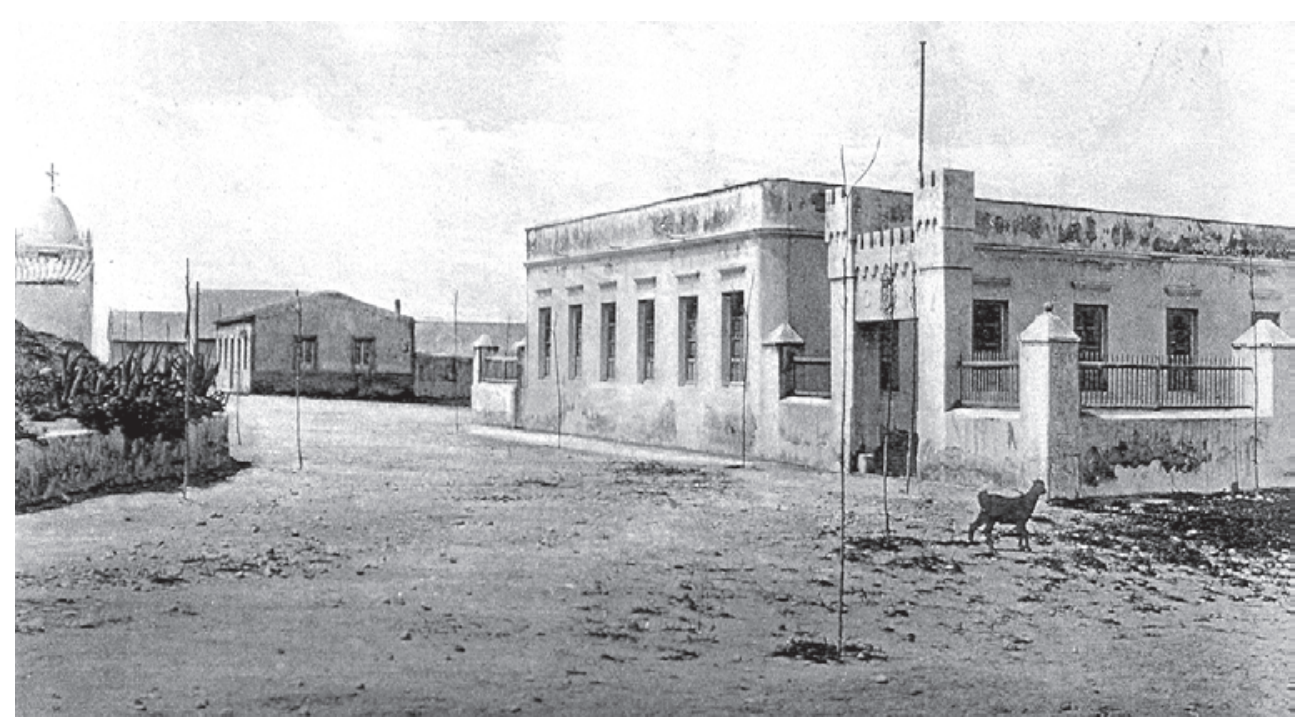

Edificio de la Comandancia Militar, capilla y campamento de Cabo del Agua.

El vapor Sirena también se utilizaba para llevar a la estación telegráfica de Chafarinas las crónicas remitidas a La Correspondencia de España por sus redactores en Melilla. Se pretendía evitar la censura militar impuesta en esta ciudad, enviando las informaciones a través del cable que unía las islas con Nemours desde el año anterior. Esta finta a la censura no par ece que diera mucho resultado ya que los telegramas se interceptaban al llegar a Madrid ${ }^{11}$.

10 El Telegrama del Rif 18/08/1909.

11 Las comunicaciones marítimas de Melilla en 1909. 


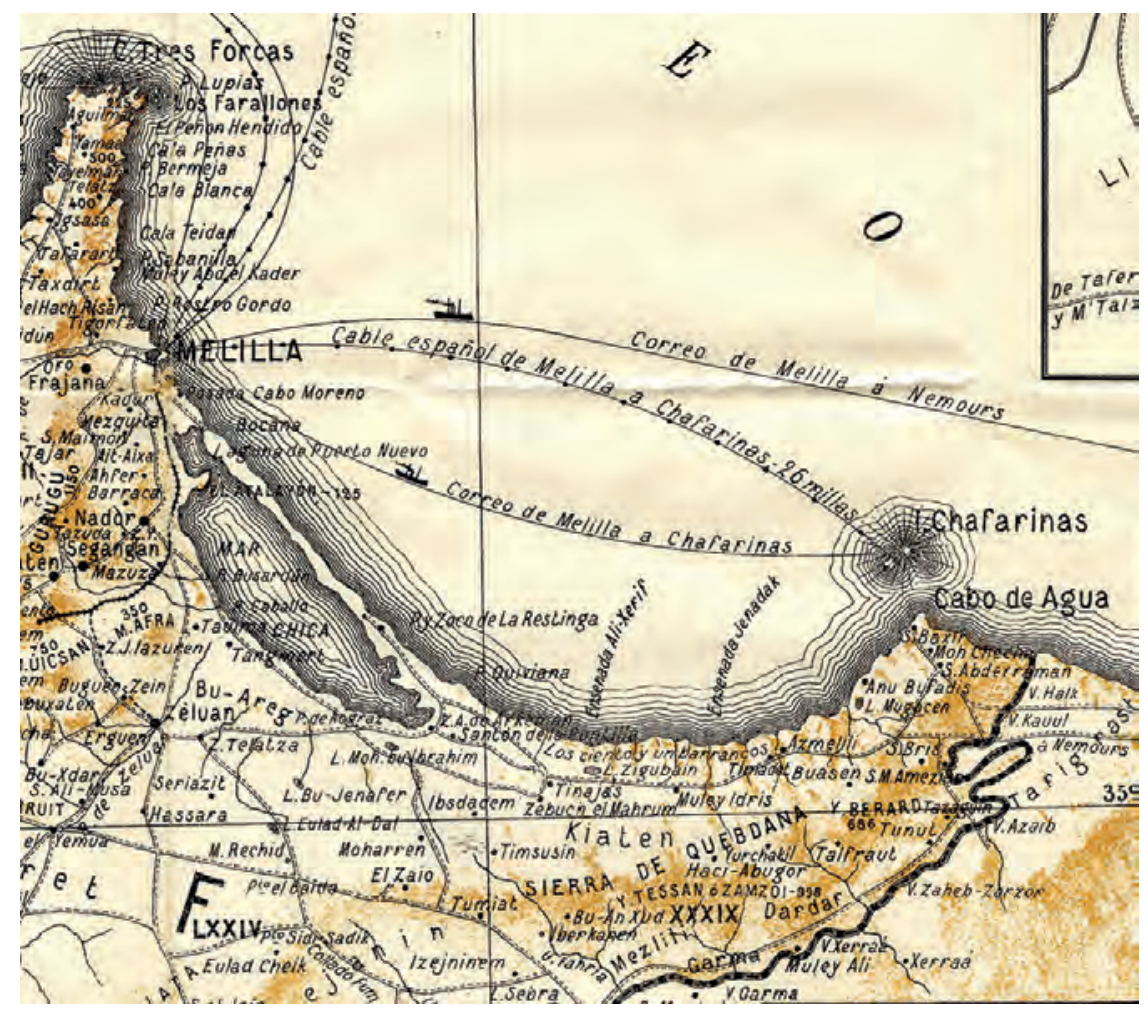

Plano con indicación del cable español de Melilla a Chafarinas, 26 millas.

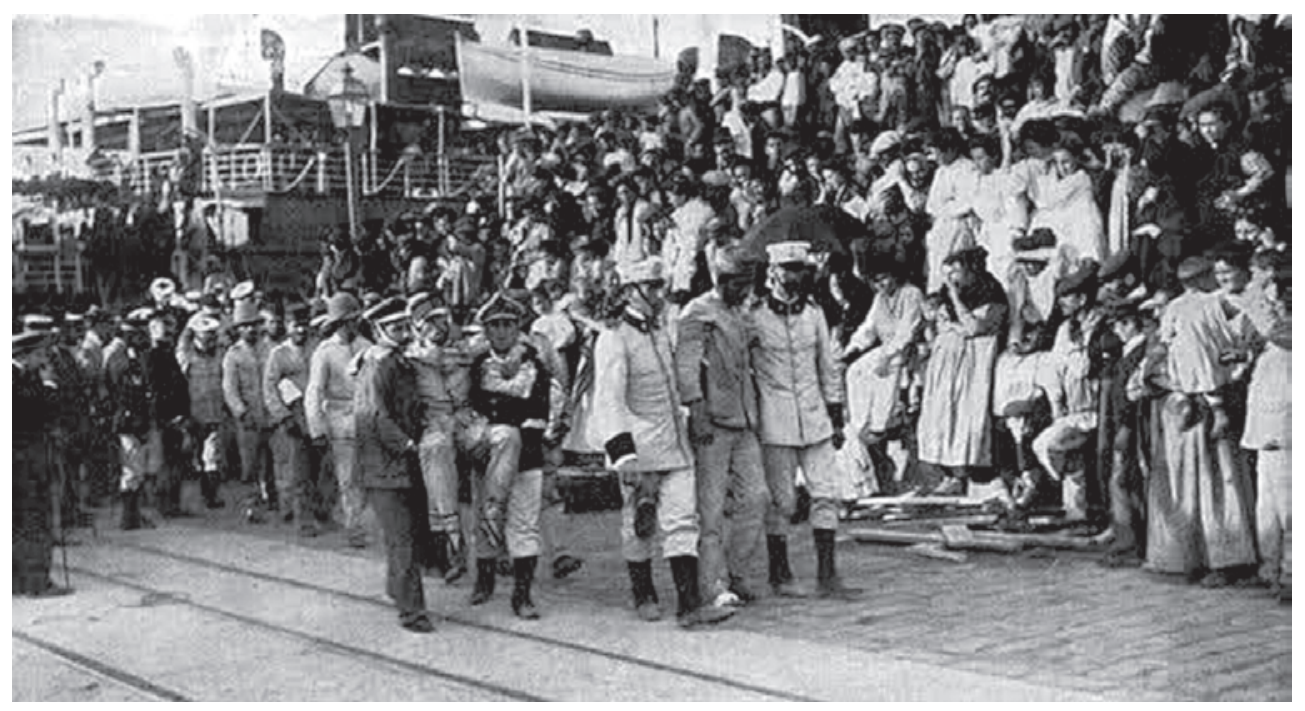

Las islas Chafarinas acogieron a muchos militares convalecientes heridos durante el conflicto, 1909. 


\section{LA EXPLOTACIÓN PESQUERA DE LAS AGUAS DE CHAFARINAS}

\section{La comisión científica de 1908: la oceanog rafía española se interesa por Chafarinas}

En 1908, las aguas entre el cabo Tres Forcas, Chafarinas y Cabo del Agua fueron objeto de una de las pimeras campañas de investigación realizadas por el Laboratorio de Biología Marina de Baleares que dirigía el eminente científico y político republicano Odón de Buen, catedrático de Zoología en la Universidad de Barcelona y senador por dic ha ciudad. Esta institución sería el ger men del Instituto Español de Oceanografía.

Ya en 1877 el príncipeAlberto de Mónaco, padre de la oceanografía, visitó Chafarinas con su y ate y laboratorio flotante "La Girondelle" en un viaje que también le llevó a Melilla, Alborán y Orán ${ }^{12}$.

Odón de Buen llegó a Melilla a primeros de julio de 1908 y el 20 de ese mes visitó Chafarinas por primera vez. Los trabajos oceanográficos se llevaron a cabo por varios científicos bajo la dir ección de Odón de Buen. Entre estos se encontraban Luis Lozano encargado del estudio de la funa marina y CarlosVarela del estudio del plancton. Estos trabajos se complementar on con sondeos y dragados para determinar la naturaleza de los fondos marinos. La comisión científica pudo constatar la gran riqueza pesquera de estas aguas debido a la influencia de las corrientes del Estrecho de Gibraltar que posibilitaba el que se encontraran especies propias del Atlántico. Esta primera campaña de investigación finalizó en septiembre de ese año. En 1909 se reanudaron los trabajos hasta que fueron interrumpidos por el estallido de la guerra contra las cabilas de Guelaya, no volviendo a reiniciarlos hasta julio de 1910. En esta ocasión la comisión científica dispuso ya de un laúd, llamado Averroes, con un patrón y tres marineros, dedicado a las investigaciones pesqueras.

\section{El despegue pesquero}

Con la ocupación de las comarcas de Guela ya y Quebdana, se abrió un extenso litoral a la explotación de los buques pesqueros españoles. La riqueza de estas aguas, que era conocida de antiguo por los hombres de la mar, acababa de

12 La Época 28/07/1877. 
constatarse científicamente por los trabajos de la comisión encabezada por Odón de Buen. Las especies de peces pr esentes en las aguas de Chaf arinas variaban estacionalmente, siendo en los meses de primavera y verano cuando más abundante era la pesca especialmente de sardinas y boquerones que atraían a bonitos y atunes que utilizaban el canal entre las islas y Cabo delAgua para sus migraciones y como zona de engorde de los alevines, lo que dio pie a proyectos de instalación de almadrabas que no se llevaron finalmente a término.

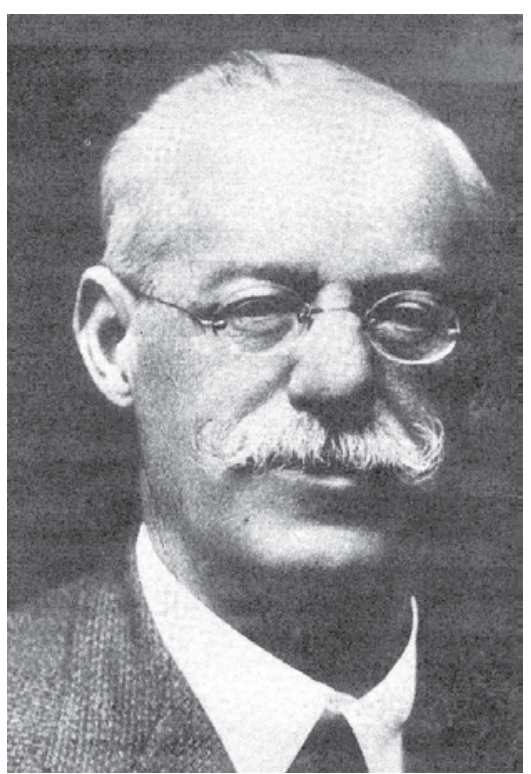

Odón de Buen, fundador del Instituto Español de Oceanografía e iniciador del estudio de la oceanografía en España, pasaría también por las islas Chafarinas en el año 1908.

En principio, las Chafarinas quedaron un poco al margen del desarollo de la industria pesquera en Melilla debido a que las barcas utilizadas para $\mathrm{f}$ aenar eran a vela y había que tener en cuenta las 24 millas que las separaban de Melilla. Desde aquel puerto se exportaban las capturas a la Península, y era una distancia considerable para una embarcación de este tipo debido sobr e todo a las calmas que a veces se producen en estas aguas y que se carecía de medios para conservar el pescado adecuadamente durante la na vegación hasta Melilla, sobre todo en verano. Esto fue cambiando cuando se generalizaion las embarcaciones a vapor y motor. El verano de 1916 fue famoso por las capturas de a tún en Chafar inas dándose días de conseguir de 1000 a 1500 piezas por barç con tallas de entre 2 
a 2,5 kilos, que para un đún son pequeñas y denotan que se estaba sobæexplotando el caladero desde el principio ${ }^{13}$.

Posteriormente empezaron a faenar en estas aguas las embarcaciones de cerco con luz, las conocidas como "traíñas", que, al utilizar redes de mallas más pequeñas que las del arte tradicional del sardinal, aumentaban las capturas con peces de menos talla.

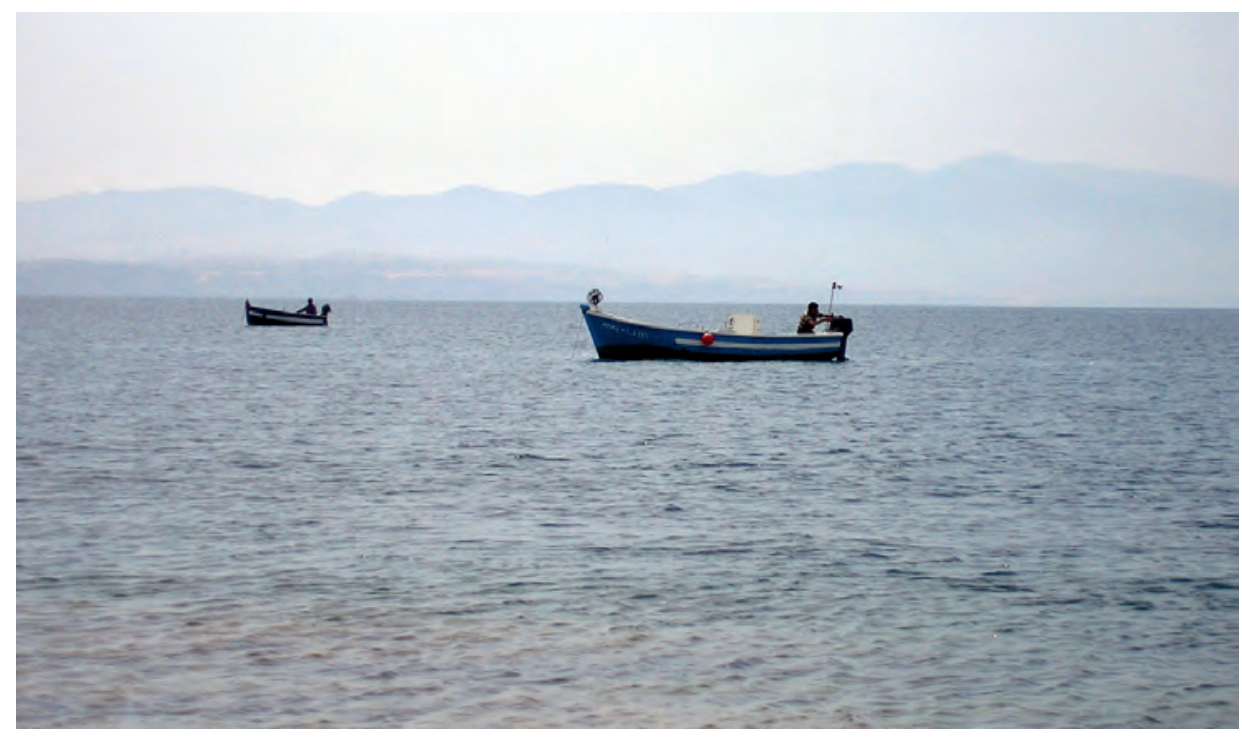

Barcos faenando en las inmediaciones de las islas en la actualidad.

Parte de estas capturas se acondicionaban con sal o hielo para su exportación a la Península y otra par te se consumía en Melilla y la zona circundante . También existían en Melilla fábricas de salazón y conservas que manufacturaban sardinas, boquerones para anchoas y atún. Hubo proyectos para establecer factorías conserveras en las mismas Chafarinas pero no prosperaron.

Aunque estas capturas, normalmente, no se descargaban ni se manuficturaban en Chafarinas, los pesqueros que fienaban en sus aguas utilizaban el pueto de Isabel II como lugar de refugio en mal tiempo, para aprovisionarse, especialmente de pan, y tomar un descanso visitando sus taber nas, lo que generó un cierto negocio para los comerciantes de las islas.

13 Algunos datos sobre el sector pesquero melillense I. 


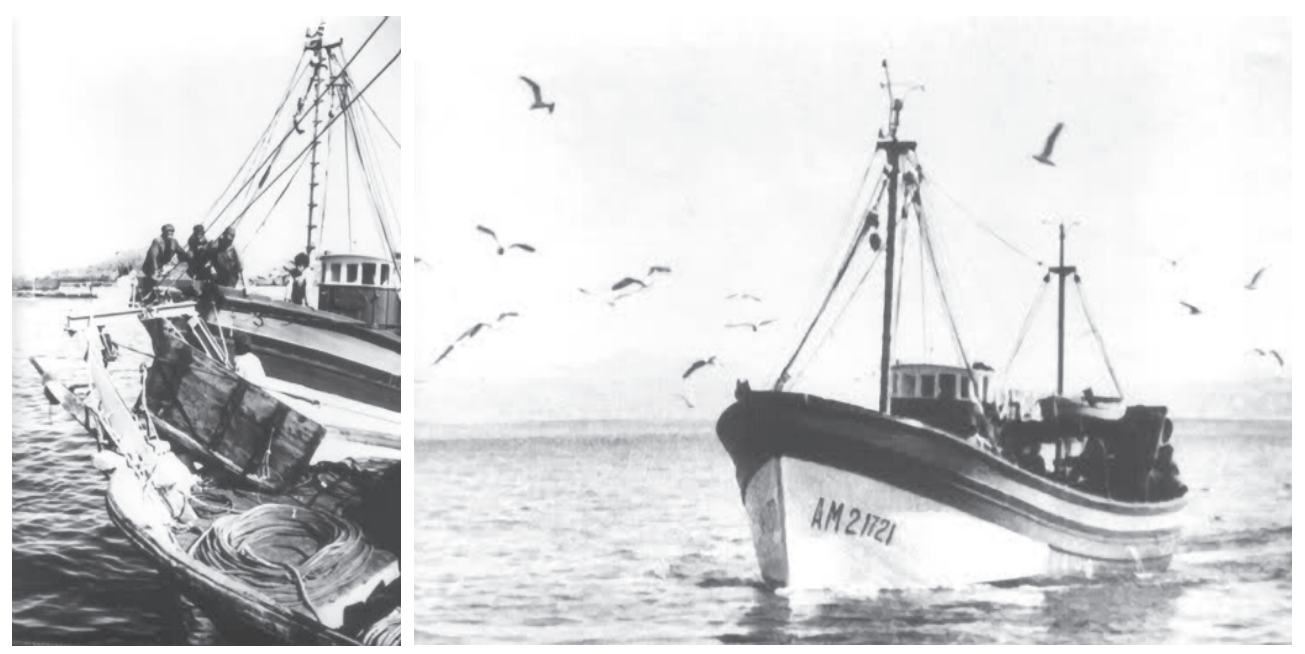

Pesqueros en las islas en los años 70.

\section{LAS CAMPAÑAS DE MARRUECOSY EL PROTECTORADO}

\section{Chafarinas durante las campañas de Marruecos}

Al igual que en la Guerra de 1909, el papel que jugó Chafarinas durante las campañas militares de ocupación del ter ritorio correspondiente al Protectorado Español sobre el norte de Marruecos, fue esencialmente secundario y a diferencia de Melilla, que vivió un extraordinario crecimiento económico, poblacional y urbanístico al calor de estas campañas militares, Chafarinas no obtuvo muchos beneficios de esta situación. Salvo la llegada del alumbrado eléctrico en el año de 1922, no se produjeron muchas mejoras en las condiciones de vida de los isleños.

La mayor implicación de Chafarinas en la guer ra coincidió con el llamado Desastre de Annual y el consiguiente leantamiento de las cabilas contras las topas españolas. Muchos quebdaníes se unieron al levantamiento y las autoridades militares de la zona ordenar on la evacuación de las posiciones del inter ior. Cabo del Agua se mantuvo en poder de España pero los civiles fueron evacuados a Chafarinas que al mando del comandante Arsenio Fuentes se convirtió en la retaguardia de Cabo del Agua. Como en 1909, en Isabel II se estableció un depósito de carbón para la Armada. En estos primeros momentos fue el cañonero Bonifaz el encargado de proteger con sus fuegos la posición de Cabo del Agua y las comunicaciones entre esta posición y las islas de donde les llegaban refuerzos y víveres. 


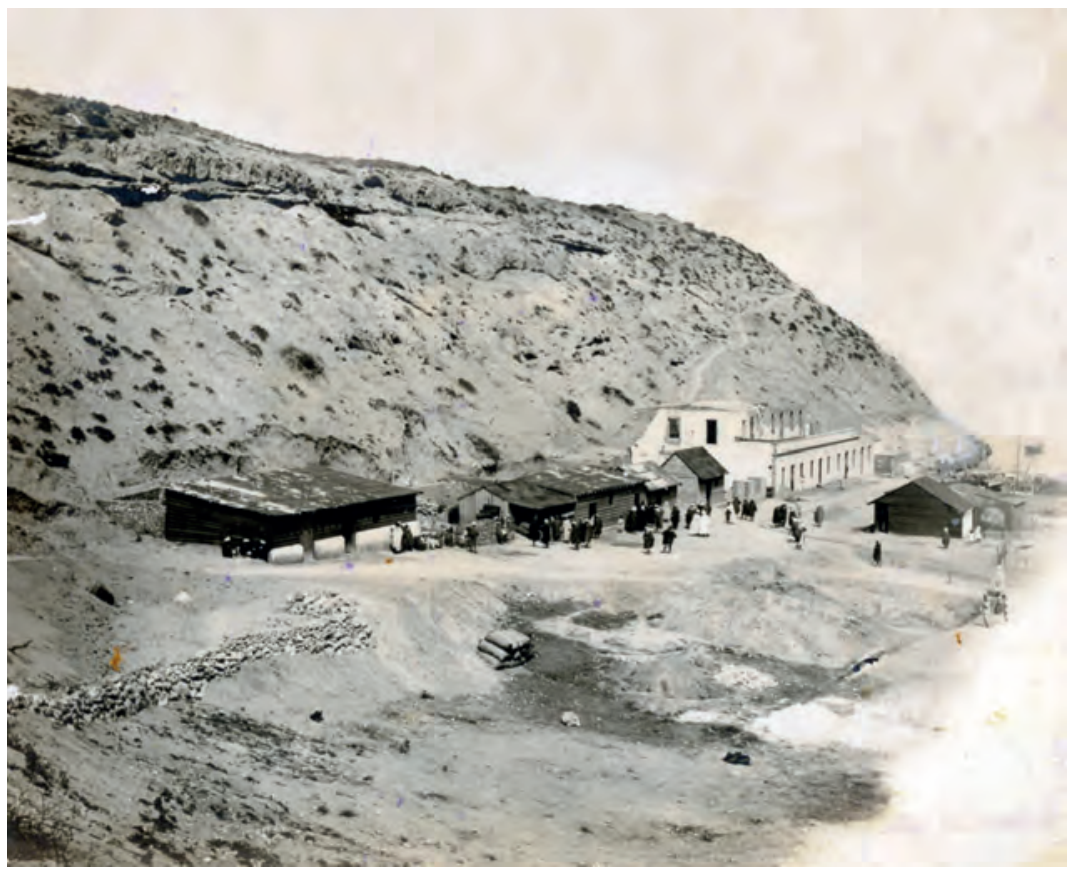

Campamento de Cabo del Agua, 1909.FCOML.

Otra labor desempeñada por Chafarinas y su vecindario fue el ofrecer refugio a las familias de españoles que habían tenido que huir del leantamiento de las cabilas. Unas pasaron directamente a Chafarinas desde Cabo del Agua y otras desde zona francesa. A primeros de agosto había 180 per sonas refugiadas en la isla y se contabilizaban unas mil repartidas entre las poblaciones de la zona francesa de Port Say, Berkane y Uxda que se pensaban r epatriar vía Chafarinas ${ }^{14}$. Estas personas llegaban prácticamente sin recursos y eran las autoridades militares y el vecindario los encargados de ofrecerles ayuda y alojamiento. En septiembre de ese año se acordó por las autor idades militares confiscar los bienes que poseyeran en las islas los quebdaníes que se hubieran unido al levantamiento ${ }^{15}$.

Igual que en 1909, se decidió enviar a las islas desde Melilla a los soldados heridos y enfermos convalecientes. Este aumento de la polación generó problemas de abastecimiento por lo que la Junta deArbitrios tuvo que proceder alguna

14 La Correspondencia de España 01/08/1921.

15 El Imparcial 20/09/1921. 
vez a comprar reses y artículos de primera necesidad por su cuenta para mejorar el abastecimiento de la crecida población ${ }^{16}$.

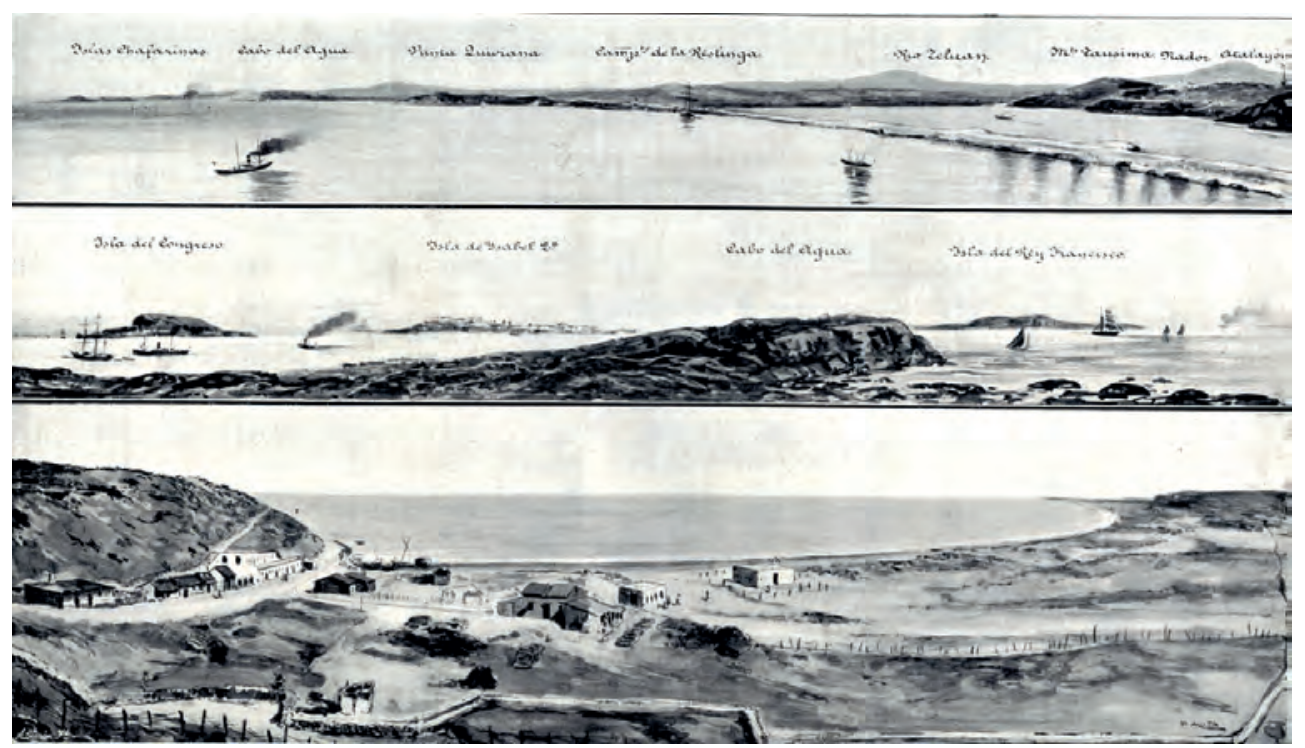

Vista de conjunto de la costa al este de Melilla; Vista general de las islas Chafarinas, desde el Cabo del Agua; Vista del campamento de Cabo del Agua.

Pasados estos primeros momentos, la situación de Chafarinas fue normalizándose y no vivieron más sobresaltos bélicos. Las islas quedaron como hospital de retaguardia y lugar de confinamiento de div ersas personas sospechosas de estar relacionadas con el levantamiento de los rifeños y guelayenses, entre ellos Dris Ben Said, del que se dice que durante su confinamiento tradujo El Quijote al árabe, Mohamed Asmani, "el moro Gato" que fue confidente de Melilla durante la guerra de 1909 y un grupo de mujeres y niños de la cabila de Beni Said que fueron confinadas como rehenes para garantizar la sumisión de didha cabila. Tras la rendición de Abdelkrim, también estuvo preso en las islas Hamed Budra, uno de sus hombres de confianza.

Junto a estos confinados musulmanes, también sufrieron prisión en Chafarinas militares españoles condenados por su actuación durante el Desaste de Annual. Entre estos militar es se encontraban los excor oneles Jiménez Arroyo y Ros, el coronel de intendencia Rafael Gallego, el comandante de Ceriñola Larrea, el capi-

16 El Imparcial 13/11/1921. 
tán Civantos y los tenientes Plaja y Dapena. En poco tiempo estuvier on todos libres, unos por cumplir condena y otros beneficiados por una amnistía ${ }^{17}$.

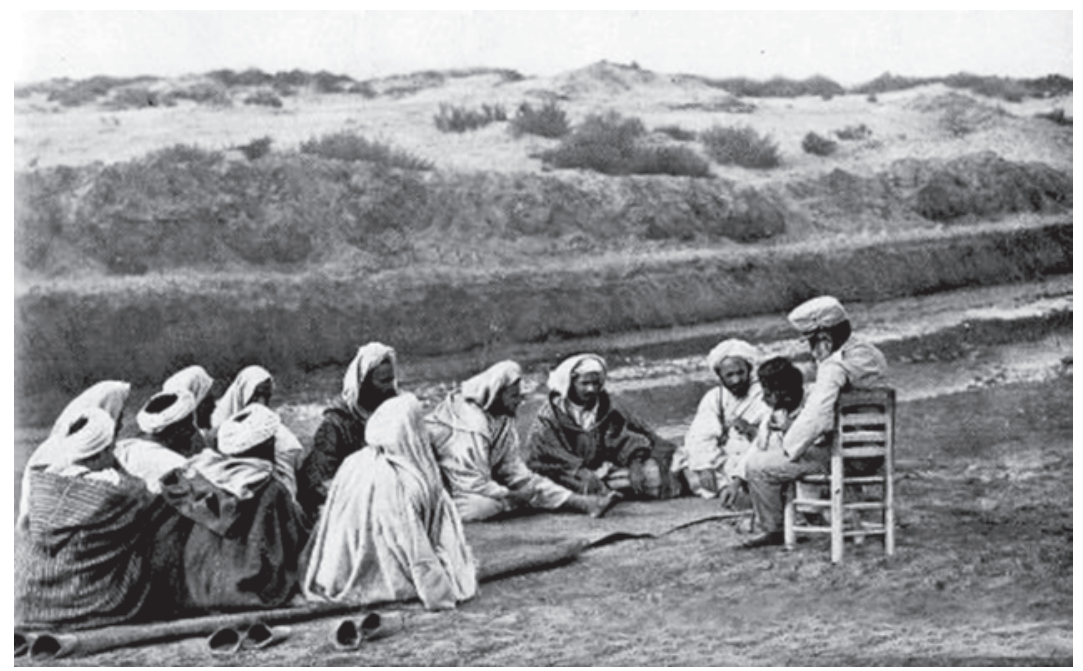

General Marina con los confidentes marroquíes durante la guerra de 1909.

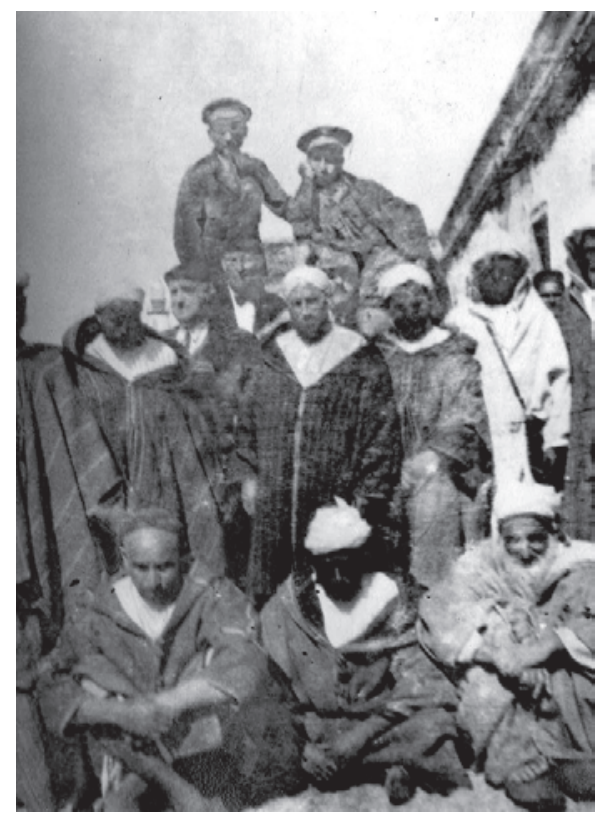

Presos musulmanes confinados en las islas Chafarinas a principios del siglo XX.

17 LaVoz 24/07/1924. 


\section{El Protectorado}

La finalización de las operaciones militares y la implantación del Protectorado Español en el norte de Marruecos no trajeron ninguna novedad a Chafarinas que prosiguió su lento pero imparable declive.

La necesidad de desarrollar el territorio sometido a España para cimentar la pacificación, llevó a primar los poblados como Villa Sanjurjo o Cabo delAgua frente a las antiguas posesiones españolas como Alhucemas, Peñón de Vélez o Chafarinas. En septiembre de 1926 se suprimieron las comandancias militares de los peñones y Chafarinas que quedaron subordinadas a las deTorres de Alcalá, Villa Sanjurjo y Cabo del Agua respectivamente ${ }^{18}$. En el caso de Chaf arinas y fruto de la reestructuración de la Circunscripción de Melilla se retiró el destacamento de infantería de Cabo del Agua con lo que la Comandancia Militar volvió a Chafarinas ${ }^{19}$.

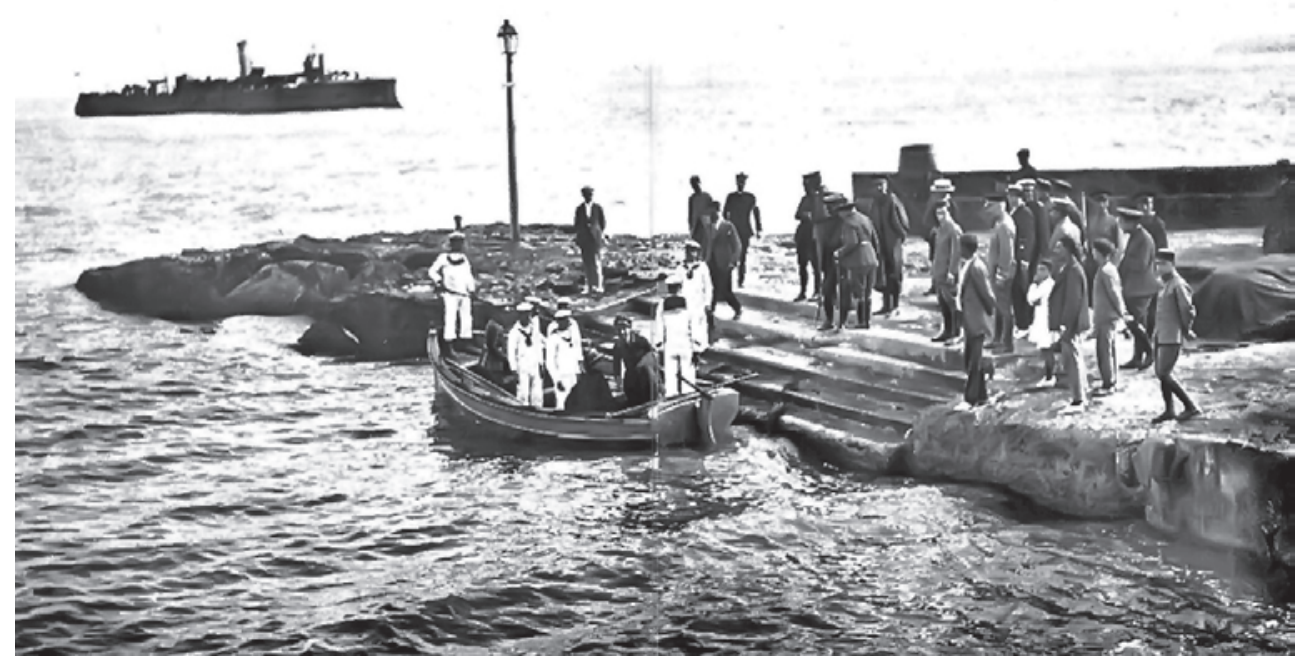

Visita a Chafarinas del comandante general de Melilla, general Losada. Revista Mundo Gráfico, 1922.

En el terreno económico, las ventajas del Puerto Franco quedaban mermadas por los impuestos que debían satisfacer las mercancías al entrar en Marruecos,

18 LaVoz 16/09/1926.

19 La Correspondencia Militar 25/10/1928. 
entrada fiscalizada por la administración de aduanas del Protectorado. Para intentar reforzar el comercio entre las plazas españolas y el ter ritorio bajo administración española se creó por Real Decreto de 3 de abr il de 1913 una comisión que estudiara medidas para pr omocionarlo ${ }^{20}$. Esta comisión pr opuso reducir los gravámenes que se aplicaban por las Juntas deArbitrios a las mercancías en tránsito a Marruecos y una r educción del precio de los fletes a las plazas españolas para hacer competitivas estas mercancías ${ }^{21}$. Estas propuestas no acabaron de convertirse en realidades. A la vez, por Dahir publicado en ese mismo año de 1913 se autorizaba la apertura de puertos comerciales en Cabo del Agua, Zoco del Arbaa de Arkeman, Sidi Musa y Nador. Aunque Cabo del Agua llegó a tener aduana, lo que, legalmente, posibilitaba las transacciones con Chafainas, las líneas del comercio se desplazaron a Melilla y esta flta de actividad comercial hizo que en 1934 se supirmiese la Intervención del Puerto Franco de Chafarinas ${ }^{22}$.

Ejemplo de esta decadencia fue el que para 1926, las comunicaciones marítimas entre Chafarinas y Melilla se limitaron a un viaje semanal con salida los sábados al mediodía desde Melilla y vuelta el domingo . El buque utilizado, el Gandía, tenía unos 36 metr os de eslora. Con todo, las dos millas que separan Chafarinas y Cabo delAgua posibilitaban una rápida y fluida comunicación entre ambas poblaciones si el tiempo lo permitía.

La pesca en las aguas de las islas siguió siendo fuctífera pero se desarrollaba sin mucho respeto a la reglamentación oficial con el peligro que para el futuro del caladero implicaba estas acciones. En el verano de 1927 las autor idades de marina de Melilla tuvieron que trasladarse a las islas y detener siete embarcaciones pesqueras por faenar en zona prohibida. Se incautaron 145 cajas de pescado y se condujeron a Melilla las embarcaciones detenidas en espera de imponerles la sanción reglamentaria ${ }^{23}$.

Durante la dictadura de Primo de Rivera se confinaron en Isabel II varios opositores al régimen como el escritor Francisco de Cossio, Arturo Casanueva y el político y jurisconsulto Luis Jiménez deAssua.Ya en las postrimerías del reinado de Alfonso XIII, se enviaron a Chafarinas a cumplir la condena impuesta por Consejo de Guerra a los 41 sargentos y especialistas militar es que participaron en la

\footnotetext{
20 Boletín zona española 01/04/1913.

21 Boletín zona española 25/08/1913.

22 Islas Chafarinas pág. 80.

23 La Correspondencia Militar 09/08/1927.
} 
sublevación republicana de Jaca. Llegaron a las islas el 4 de abril de 1931 y con la proclamación de la República el 14 de abril fueron liberados, llegando el 15 por la noche a Melilla donde recibieron una multitudinaria y entusiasta acogida.

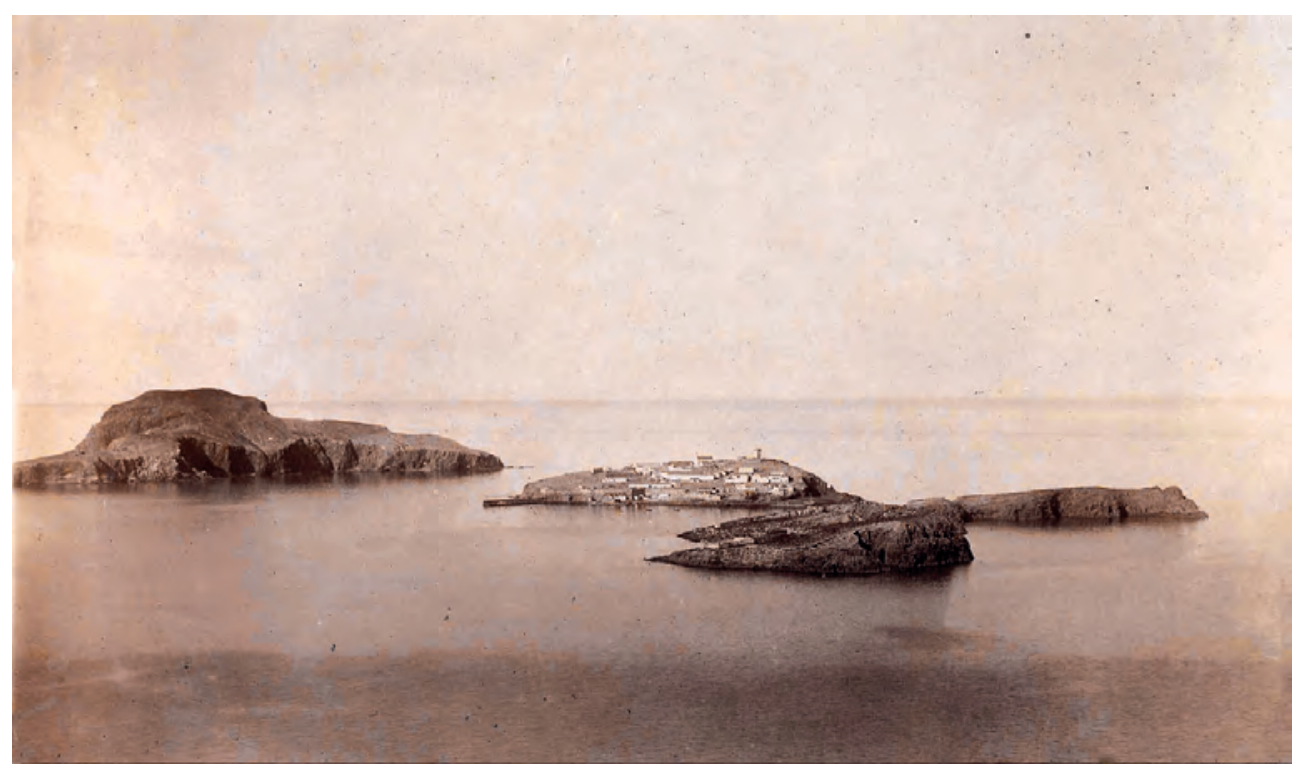

El archipiélago de las Chafarinas en una vista de los años veinte.

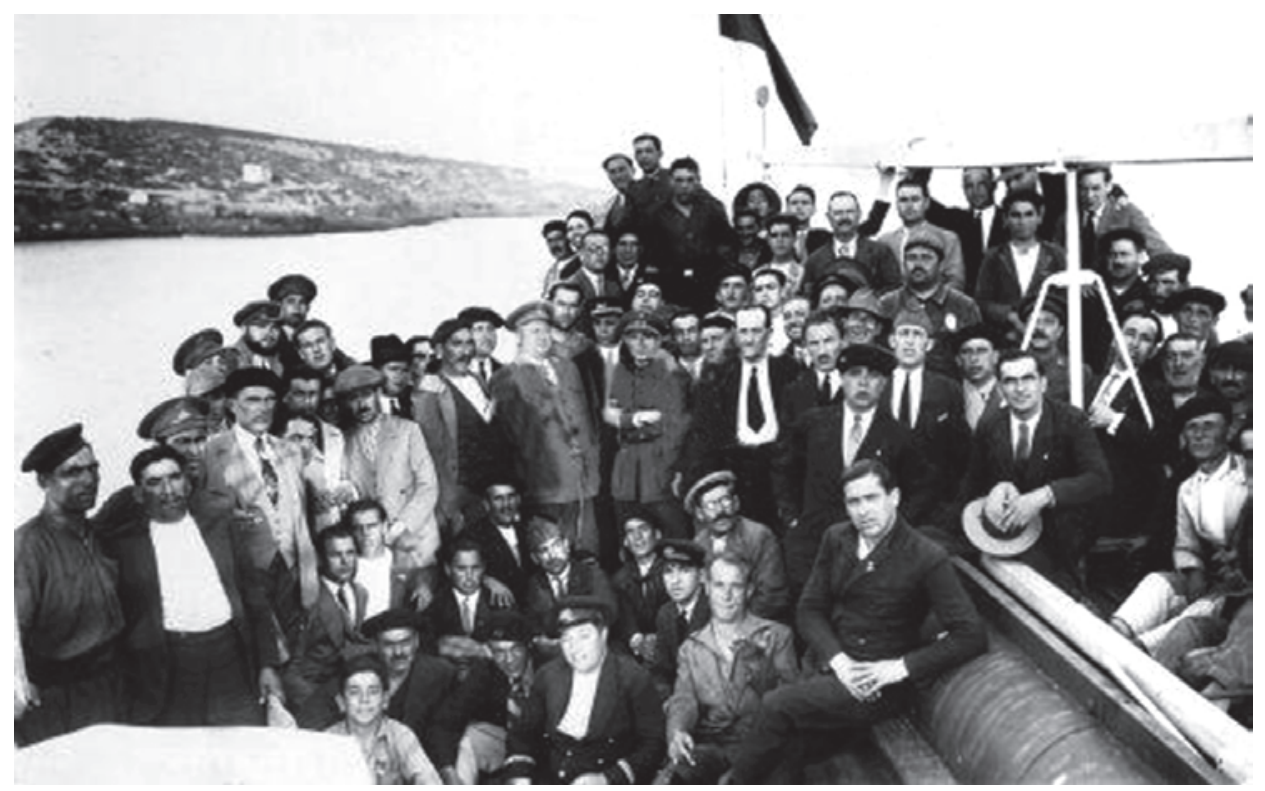

Presos de Jaca en las islas Chafarinas. Foto: Zarco y López. 


\section{República, guerra civil y posguerra}

Con la proclamación de la República, la población de Chafarinas compartió con la mayoría de los habitantes de los ter ritorios españoles del Nor te de África la reivindicación de equiparación de der echos civiles con el r esto de la nación. Esta concienciación de la ciudadanía de las islas se maerializó en algunos actos y reivindicaciones al gobierno.

El domingo 23 de agosto de 1931 se hizo entrega de una bandera republicana a la Junta de Servicios Municipales de Chafarinas. Esta bandera fue un obsequio del partido de Unión Republicana de Melilla en agradecimiento al vecindario por el trato dispensado a los desterrados por la sublevación militar de Jaca. La bandera fue conducida a las islas vía Cabo delAgua por una comisión del partido entre los que estaban Ramón y Eduardo de Bustos, significados precursores del republicanismo melillense. Según El Telegrama del Rif, los visitantes pudieron constatar el abandono que sufría Chafar inas, abandono que se hacía e vidente en el deterioro de todas las edificaciones de Isabel II ${ }^{24}$.

Con motivo de la victoria electoral del Frente Popular, una comisión formada por treinta vecinos de Chafarinas envió un telegrama de felicitación a Luis Barrena, diputado electo por Melilla, y a los líder es de los partidos del Frente Popular en el que se quejaban de la imposibilidad de ejercer su derecho al voto en la isla y solicitaban se les reconocieran los derechos civiles en Chafarinas. Por último proponían que se les cambiase los nombes a las islas por los de:Libertad, Igualdad y Fraternidad ${ }^{25}$.

La sublevación militar del 17 de julio de 1936 no tuv o eco directo en Chafarinas y la represión franquista sólo afectó a un par de v ecinos que fueron detenidos durante un tiempo ${ }^{26}$.

Las islas no sufrieron bombardeos navales y aéreos gubernamentales y los años de guerra trascurrieron sin grandes sobresaltos, salvo alguna noticia triste llegada del frente o la huida a zona francesa del pesquer o con base en Melilla “Antonio Marfil” con ocho tripulantes y que tenía autor ización de los mandos franquistas para faenar en las aguas de Chafainas. En la noche del 17 de mayo de 1937, navegaron hasta las islas como era costumbr e y, antes del amanecer, al

\footnotetext{
24 El Telegrama del Rif 25/08/1931

25 El Heraldo de Madrid 25/02/1936.

26 Islas Chafarinas pág. 84.
} 
comprobar que no había guardacostas y esquiv ando los proyectores de tier ra, pusieron rumbo a Nemours, donde llegaron sin novedad ${ }^{27}$.

La posguerra no fue tan dura como en otros lugares ya que podían aprovisionarse de alimentos en Cabo delAgua. El pescado y el pan no flttaban, aunque no fueran de muy buena calidad ${ }^{28}$.

A destacar en esos oscuros años la celebración el 6 de ener o de 1948 del centenario de la ocupación con un acto castr ense en Melilla ${ }^{29}$ y el durísimo temporal de levante de diciembre de 1949 que ocasionó g raves daños en las embarcaciones surtas en el puer to de Melilla, mientras que los pesquer os San Francisco, Luisito, Hermanos Nogueras y Pepito lo pudieron capear al resguardo de Chafarinas ${ }^{30}$.

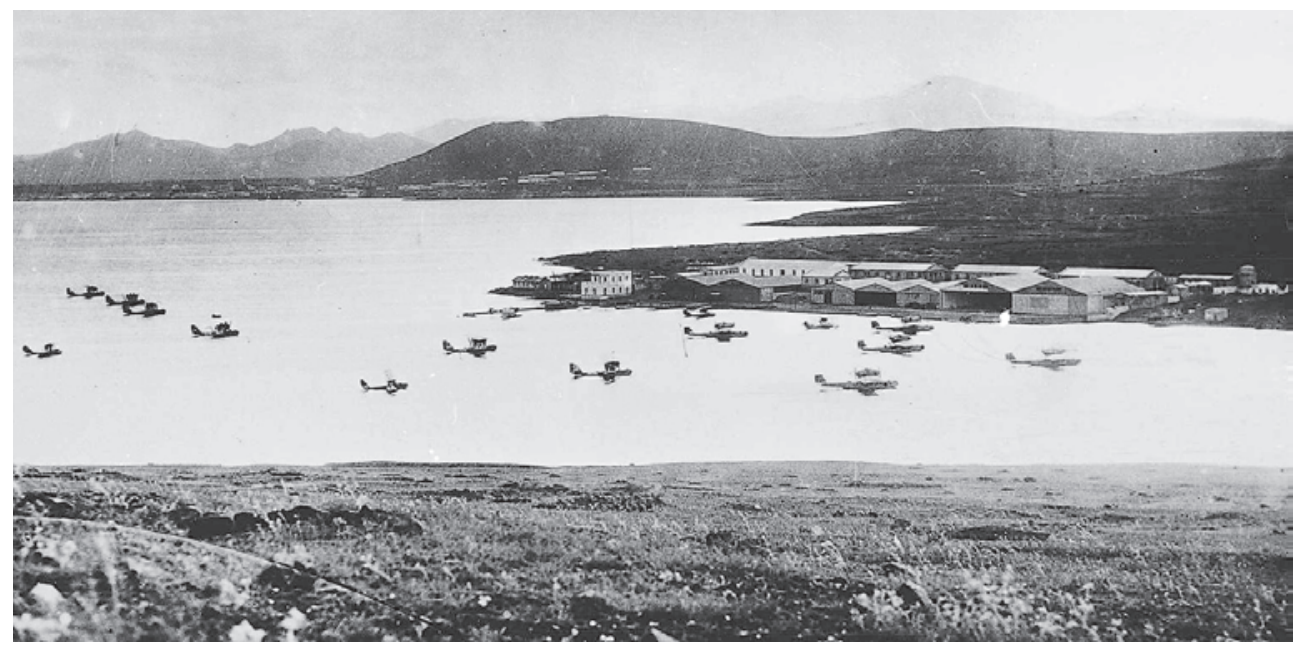

Base de hidroaviones en el Atalayón, Mar Chica, antes del estallido de la guerra civil. Archivo del Ejército del Aire, AIMM.

\section{El espejismo de la llamada vivificación de Chafarinas}

Entre 1952 y 1953, llegando ya a las postr imerías del Protectorado, la propaganda del régimen se hizo eco de una serie de proyectos y obras a efectuar en Chafarinas en lo que se denominaba "vivificación de las islas" y que según el

\footnotetext{
27 LaVoz 01/06/1937.

28 Islas Chafarinas pág. 84.

29 ABC 07/01/1948.

30 La Vanguardia 16/12/1949.
} 
diario $A B C$ señalarían "un hito en los fastos de la Histora y una prueba inconclusa de la presencia de España en Marruecos”. Entre estas obras y proyectos estaban la restauración de la iglesia y diversos edificios, reformas en el puerto para posibilitar la entrada de buques de mayor tonelaje y atuneros, un hogar del pescador, instalaciones para favorecer la industria pesquera, un parador de turismo y restablecer el servicio de transporte semanal con Melilla para "los numerosos turistas" que se esperaba visitarían las islas Aunque este plan lo presentaron dos grandes figuras del afr icanismo franquista como el teniente general García Valiño, Alto Comisario y Gobernador General de las plazas de Soberanía, y el historiador Tomás García de Figueras, volvió a quedar prácticamente en nada,como casi todos los planes elaborados para Chaf arinas. Finalmente se restauró la iglesia y algún otro edificio, se reformó la Plaza de Armas, que pasó a llamar se García Valiño, y se construyeron algunas casetas para uso de los pesqueros que tenían su base en Isabel II ${ }^{31}$. En enero de 1955 tuvo lugar la exhumación a instancias del gobierno cubano de los supuestos $r$ estos de los independentistas m uertos en Chafarinas Rafael Maceo y el coronel Juan Cintra. Las dictaduras cubana y franquista organizaron toda una serie de actos de mutuo reconocimiento coincidiendo con el traslado de los restos de ambos patriotas ${ }^{32}$.

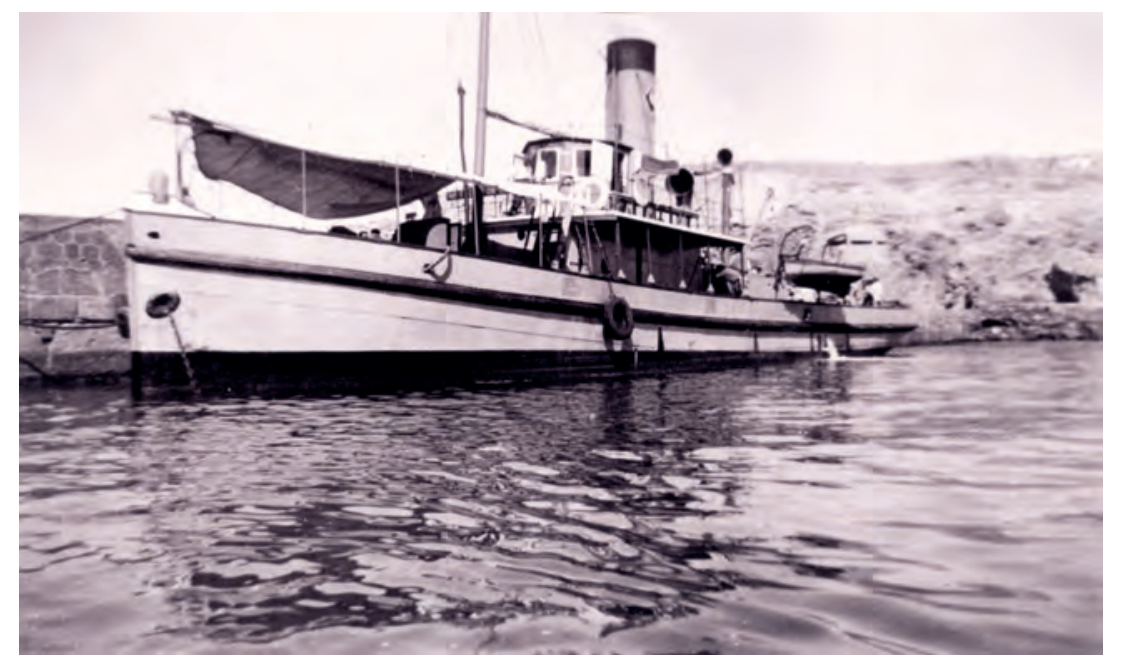

El vapor correo Triana, de Transportes Militares, atracado en el puerto de Chafarinas, permitía la comunicación con Melilla.

$31 A B C$ 19/09/1953. Islas Chafarinas págs. 89, 90, 91.

$32 A B C 22 / 01 / 1955$ y $29 / 01 / 1955$. 


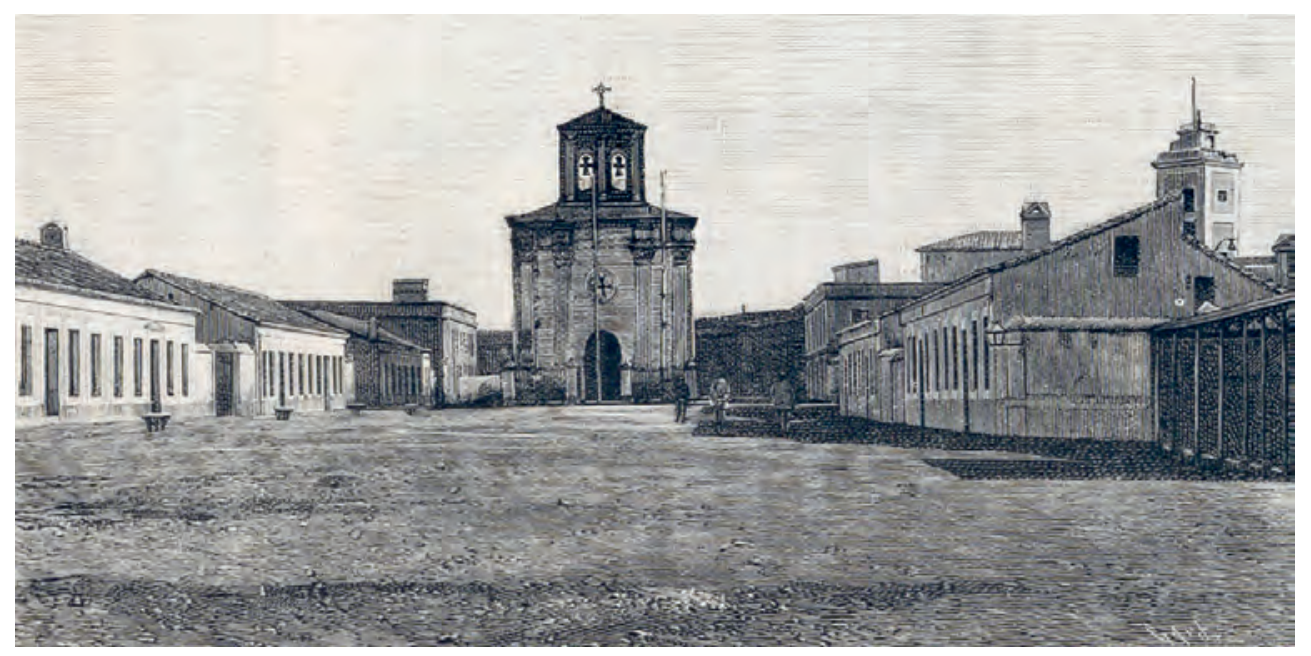

Vista general de la plaza y la iglesia en la isla de Isabel II.

(La Ilustración Española y Americana, 22 de octubre de 1893).

\section{CHAFARINAS DESDE LA INDEPENDENCIA DE MARR UECOS A LA CRISIS HISPANO - MARROQUÍ DE 1975}

\section{La independencia de Marruecos}

Entre marzo y abril de 1956 Marruecos recuperó su independencia, aunque el repliegue total de las fuerzas armadas españolas no finalizó hasta 1961.El fin del Protectorado y la desaparición de la figura delAlto Comisario, motivó los consiguientes cambios en la administración de Ceuta, Melilla y las posesiones norteafricanas, si bien Chafarinas siguió dependiendo de la Comandancia General de Melilla. Unos años después desapar eció el cargo de Comandante Militar de Chafarinas, pasando sus funciones al oficial al mando del destacamento que hacía el turno de guarnición.

En los años que siguieron a la independencia de Marruecos la vida en las islas no se vio muy alterada. Siguieron las relaciones, que podríamos llamar vecinales, con Cabo del Agua. La escasa población isleña pudo continuar abasteciéndose de productos frescos en dicha localidad y utilizar su pequeño embarcadero como ruta alternativa para acceder a Chafarinas, dada las deficientes comunicaciones marítimas que mantenían con Melilla. Los pesqueros de Cabo del Agua, traíñas en su mayoría, siguieron teniendo su base en la rada de Isabel II. Según recuerda Antonio Pardo, que vivió aquellos años en las islas, los tripulantes, una 
vez fondeado el barco, partían en el "bote de la luz" hacia tierra firme, dejando un guardián en el pesquer o, salvo que se bar runtara mal tiempo y tuviera que quedarse la tripulación entera.

En cuanto a la pesca en las aguas que $r$ odean las islas, que España nunca definió como propias, pudo seguir desar rollándose por el acuerdo comercial entre España y Marruecos de 1957 donde se garantizaba al derecho recíproco a pescar en las aguas jurisdiccionales de ambos países a sus pesqueıs según venían haciéndolo históricamente. No es hasta 1969 cuando se fima un primer acuerdo pesquero entre España y Marruecos. En dicho acuerdo se fijaban las aguas jurisdiccionales de cada país en las doce millas, aunque se seguía reconociendo los "Derechos Históricos" de los pesqueros españoles en aguas marroquíes ${ }^{33}$. Este tratado permitía el seguir faenando en las aguas de Chafar inas a los pesquer os españoles, principalmente de Melilla. Pero en pocos años iba a estallar un serio conflicto entre España y Marruecos con varios frentes, uno de ellos el pesquero.

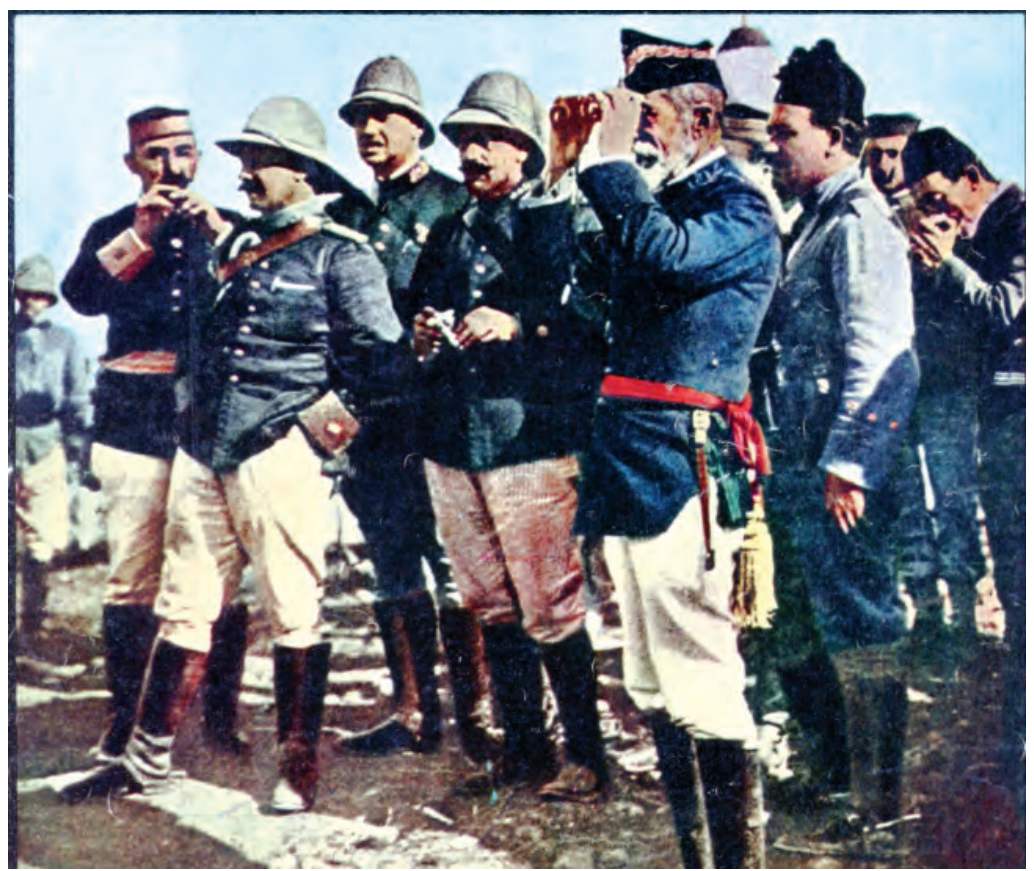

El 7 de abril de 1956, España reconoció la independencia de Marruecos. La Administración del Protectorado dejaba paso a un nuevo estatus jurídico y político.

33 BOE del 05/06/1969. 


\section{La crisis hispano - marroquí de los años setenta: Sahara, pesca y reivindica- ciones territoriales marroquíes}

El primer brote de esta crisis tuvo lugar en el ámbito pesquero. Pese a que el acuerdo de 1969 entre ambos países tenía una validez para diez años, a finales de 1972 se dio por finalizado dada su poca efectividad. Marruecos aprovecha la ocasión y a primeros de 1973 amplía a 70 millas las aguas de lo que hose conoce como zona económica exclusiva. Esto era algo que estaban imponiendo v arios países con grandes reservas pesqueras pero que toda vía no estaba r egulado internacionalmente.

En Melilla, donde se vivía la peculiar situación de que un considerab le número de pesqueros marroquíes tenían su base en su puerto, se permitía pescar a los pesqueros españoles hasta que el 2 de julio de 1973 una paullera marroquí apresa al pesquero melillense Cuarto Mandamiento que es conducido aAlhucemas. Esto hizo que la flota melillense amarrara en puerto unos días en espera de que se normalizara la situación. Llegamos así a noviembre de ese año en que se produce un nuevo incidente con las patrulleras marroquíes en aguas de Chafarinas. El 27 de ese mes fue apresado el pesquero melillense "Gutyago" cuando faenaba a pleno día a unas seis millas a le vante de las islas. Junto a éste son apr esados también el "Olvera Gallardo", el "Quiñonero" y el "Blanca Paloma", todos con matrícula de Melilla, cuando navegaban rumbo a dicho puerto. Conducidos a Alhucemas, base de las pa trulleras marroquíes, fueron liberados el 30 de noviembre, llegando a Melilla esa misma noche ${ }^{34}$.

Estos problemas pesqueros pudieron ser resueltos a base de acuerdos y negociaciones puntuales, pero las pr etensiones marroquíes de anexionar se el Sahara Español, cuya descolonización exigía la ONU, iba a generar una nue va crisis hispano-marroquí en la que el país alauita pr esionó a España mediante la internacionalización de sus injustificadas reivindicaciones sobre la soberanía de Ceuta, Melilla, islas Chafarinas y los peñones de Vélez y Alhucemas. El embajador marroquí ante la ONU llegó a pr esentar en febrero de 1975 una car ta al Comité de Descolonización en la que se solicitaba se incluyse a estos territorios españoles en la lista de ter ritorios a descolonizar, lo que no se tomó en cuenta por dicho comité. Finalmente la firma del llamado Acuerdo de Madrid el 14 de

\footnotetext{
34 El Telegrama de Melilla y ABC del 28/11/1973. LaVanguardia 01/12/1973.
} 
noviembre de 1975 por los que España cedía la administración del Sahara a Marruecos y Mauritania calmó la situación.

\section{El ocaso de la flota pesquera española en Chafarinas}

Tras los acuerdos de Madrid se normalizaron las relaciones pesqueras y los pocos barcos que quedaban en Melilla y otr os llegados de Almería, Adra y Barbate, principalmente, volvieron a faenar en aguas de Chafarinas en unos años de abundancia de capturas. José López López, patrón de un pesquer o de Adra que faenaba en Chafarinas, recuerda este momento como los años del"boquerón de Melilla”. El abuso de las capturas y la utilización de explosivos por españoles y marroquíes para hacer aflorar el pescado dier on al traste con el calader o a mediados de los ochenta.

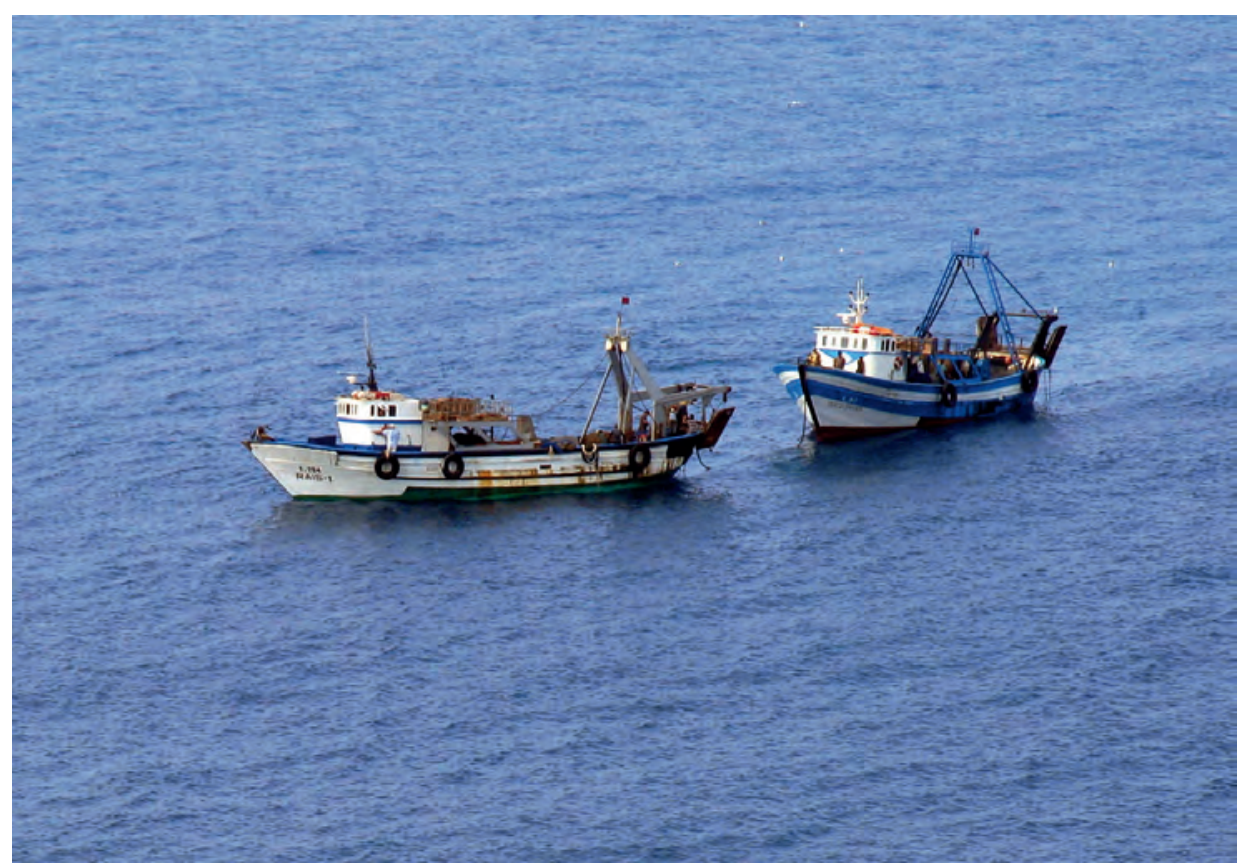

Pesca con redes de arrastre en la actualidad. La actividad de estos arrastreros está esquilmando los fondos protegidos de las islas.

Con todo, mientras estuvieron vigentes los acuerdos pesquer os con Marruecos, hubo barcos españoles faenando en aguas de Chafarinas y utilizando las islas como puer to de refugio cuando era necesar io, como el pesquer o "Mar y 
Sol” que en junio de 1996 fondeó en la rada de Isabel II con una vía de agua. La guarnición de la isla, especialmente el destacamento de la Compañía de Mar, le prestó apoyo en la medida de sus posibilidades Sin embargo, necesitado el barco de más asistencia debido a que controlaban difícilmente la vía de agua y empeoraba el tiempo de levante, se envió desde Melilla a la embarcación de salumento "Salvamar Uno", mandada en esos días por el autor de estas líneas, con personal especializado para realizar una reparación de urgencia que permitió al pesquero llegar en seguridad hasta su base en el puerto de Almería.

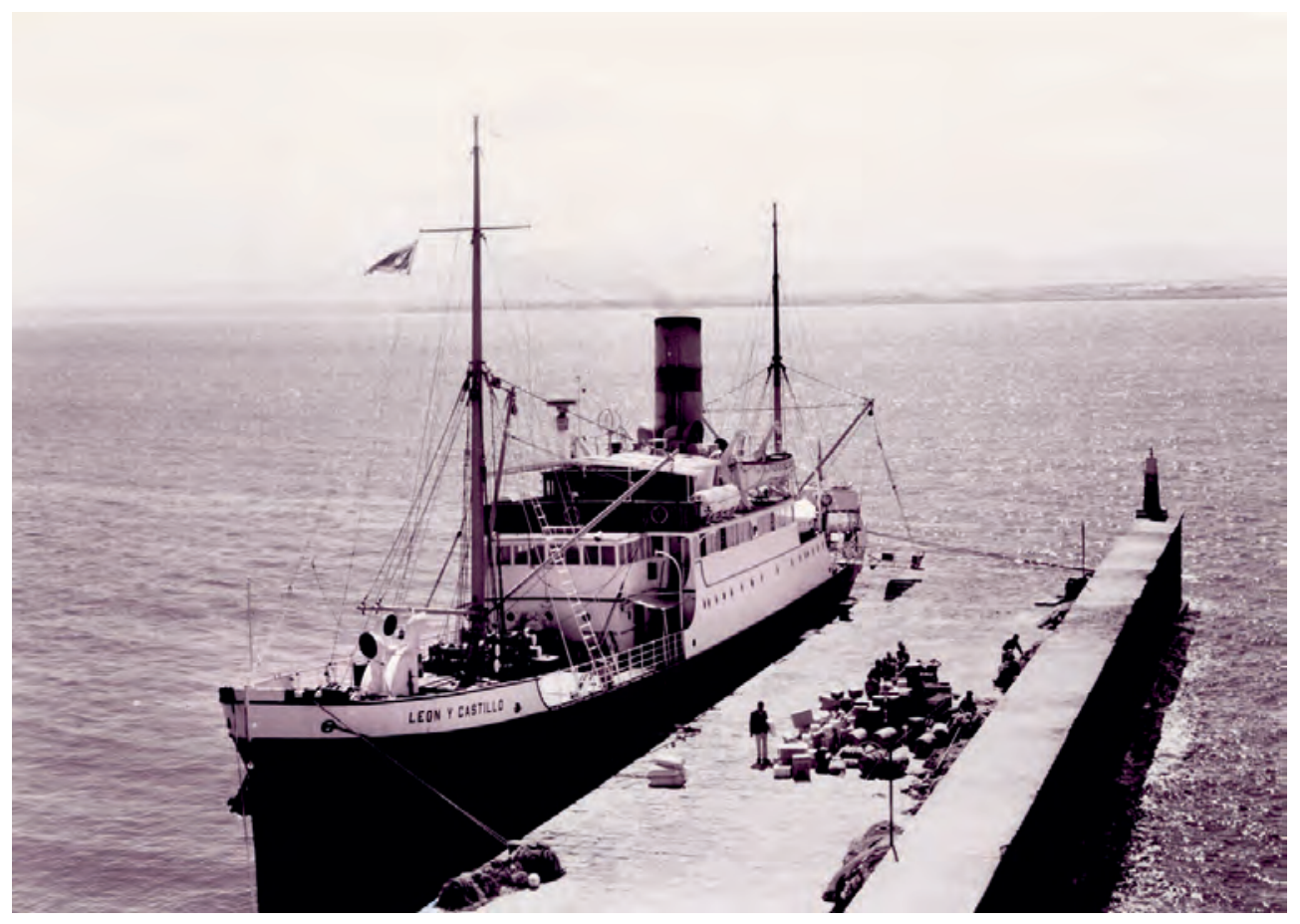

El León y Castillo atracado en el Titán, puerto de Chafarinas.

\section{CHAFARINAS EN LA ACTUALIDAD}

\section{El final de la población civil residente en Chafarinas}

A finales de la década de los setenta la situación de Chafrinas era de franca decadencia. Su guarnición se reducía a una compañía de Regulares al mando de un capitán y un destacamento de la Compañía de Mar al mando de un sargento. 
Los civiles residentes en Isabel II se limitaban a un telegafista, un panadero y un farero, aunque en aquellos años toda vía vivían allí, temporalmente, algún que otro familiar de los mandos de la guarnición y de los civiles allí destinados. Las comunicaciones con Melilla se llevaban a cabo cada quince días por el viejo buque de Trasmediterránea "León y Castillo". Los contactos con Cabo delAgua los realizaba un mar roquí, conocido por "El Largo", con su bote ${ }^{35}$. Esta exigua población civil fue dejando las islas pocos años después y sus cargos desapaecieron, como el caso deTelégrafos o del encargado del faro, o fueron ocupados por personal del Ministerio de Defensa que se tur naba cada mes, como era el caso del panadero o el mecánico naval. LópezTirado fecha en 1986 el fin de la población civil residente, con la jubilación de Manuel González Madolell encargado del puerto y del faro ${ }^{36}$. Ese mismo año se suspendió definitiv amente la línea marítima que unía Melilla y Chafarinas.

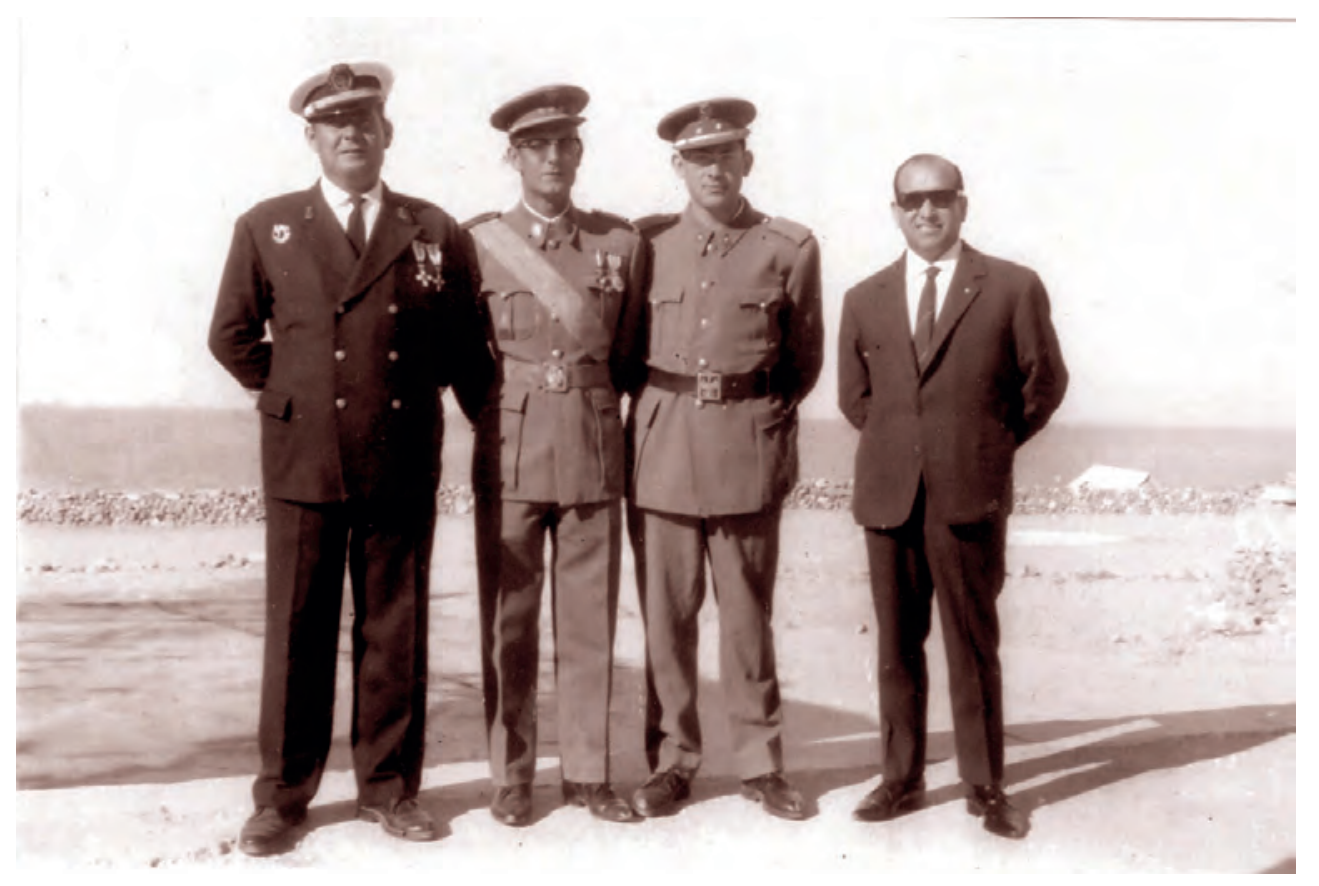

Militares de la guarnición de las islas y farero en 1964.

35 Reportaje de Alberto Miguez en LaVanguardia del 16/07/1977.

36 Islas Chafarinas pág. 108. 


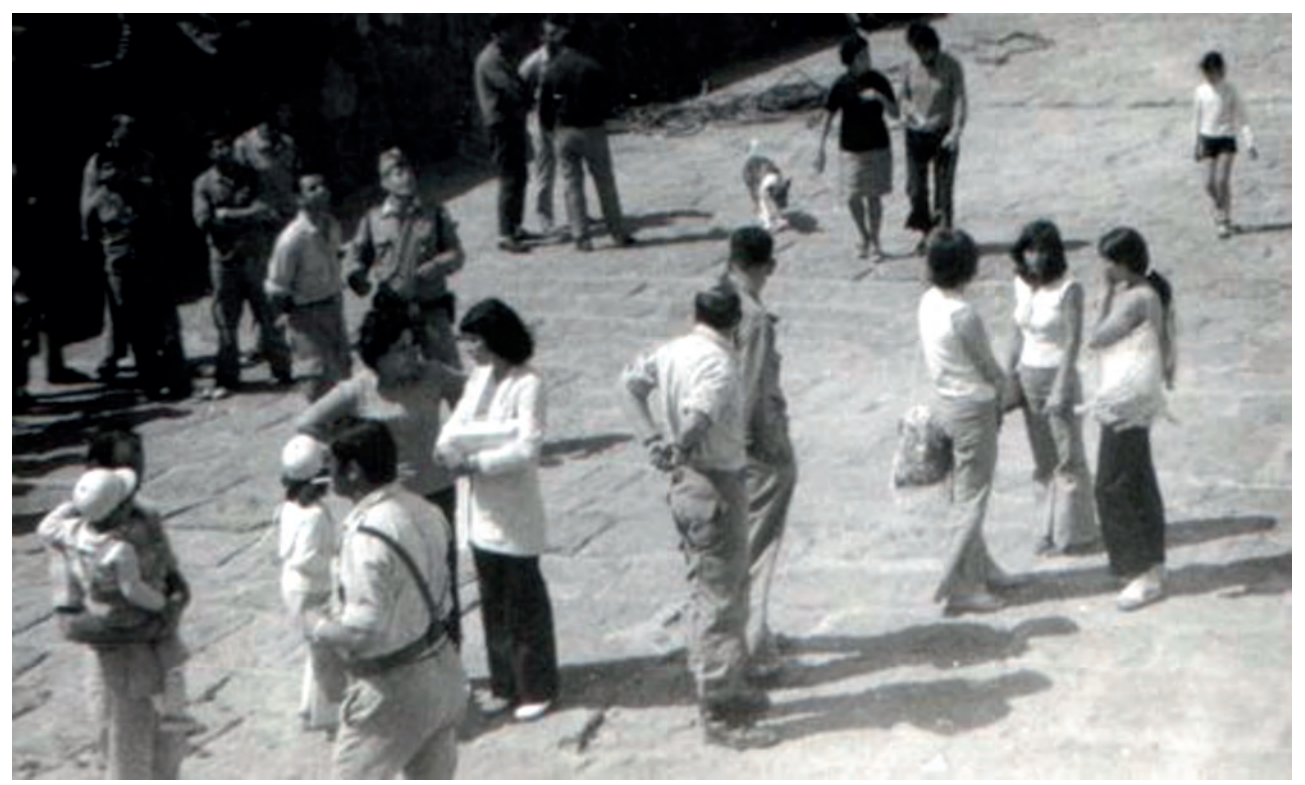

Población civil en el puerto Titán, isla de Isabel II, en los años 70.

\section{El presente y futuro de Chafarinas}

Siendo territorio bajo administración militar, en las islas se han dejado sentir los efectos de la profesionalización, modernización, reducción y reorganización de efectivos y medios que han experimentado las fuerzas armadas en estos últimos años.

La reducción de efectivos destinados en Melilla como consecuencia de la profesionalización del ejército trajo consigo la consiguiente educción de la guarnición de Chafarinas, especialmente de la Compañía de Mar , que vio también reducido el número de sus embarcaciones en Chafarinas cuando a mediados de los noventa se retiró a Melilla el último de la serie de los "bote mixto" que prestaba servicio en las islas. En el año 2000 se dio de baja al buque "Capitán Mayoral”, un carguero de 399 TRB perteneciente a la unidad de apo yo logístico de Melilla y tripulado por personal civil de Defensa que hacía servicio a las Chafarinas y los peñones de Alhucemas y Vélez. Los relevos de personal y emergencias se venían ya realizando mediante helicópteros. Tras la baja del Capitán Mayoral, las comunicaciones marítimas con Chafarinas quedaron limitadas a los aljibes de la Armada, que transportaban materiales y vituallas a las islas en los viajes para aprovisionarlas de agua potable. En estos años se supr imieron los turnos mensuales que realizaban en las islas los panaderos y mecánicos navales de Defensa. 


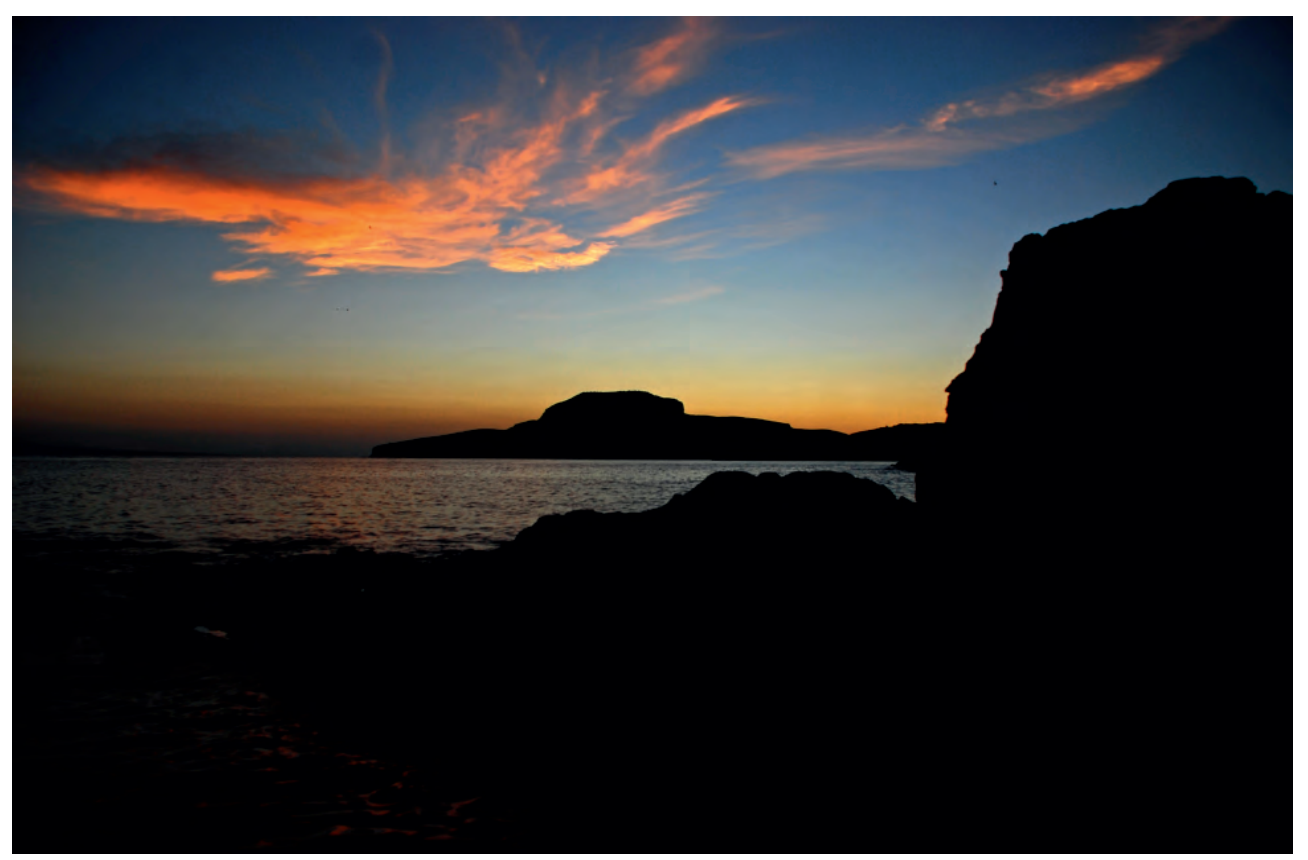

Un atardecer en las islas Chafarinas desde la isla del Rey. Fuente: José María Peñuela.

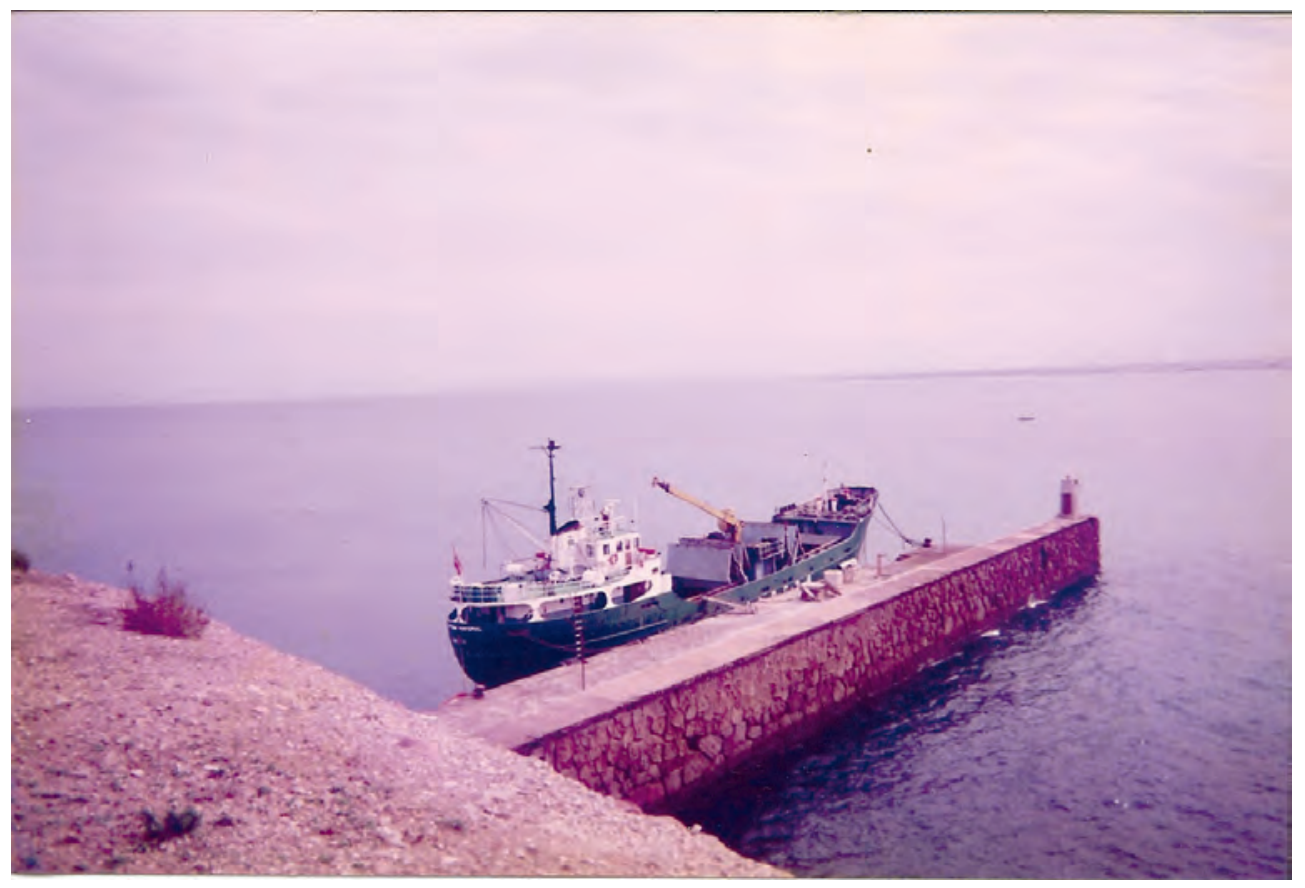

El “Capitán Mayoral” atracado en el muelle de Chafarinas. 


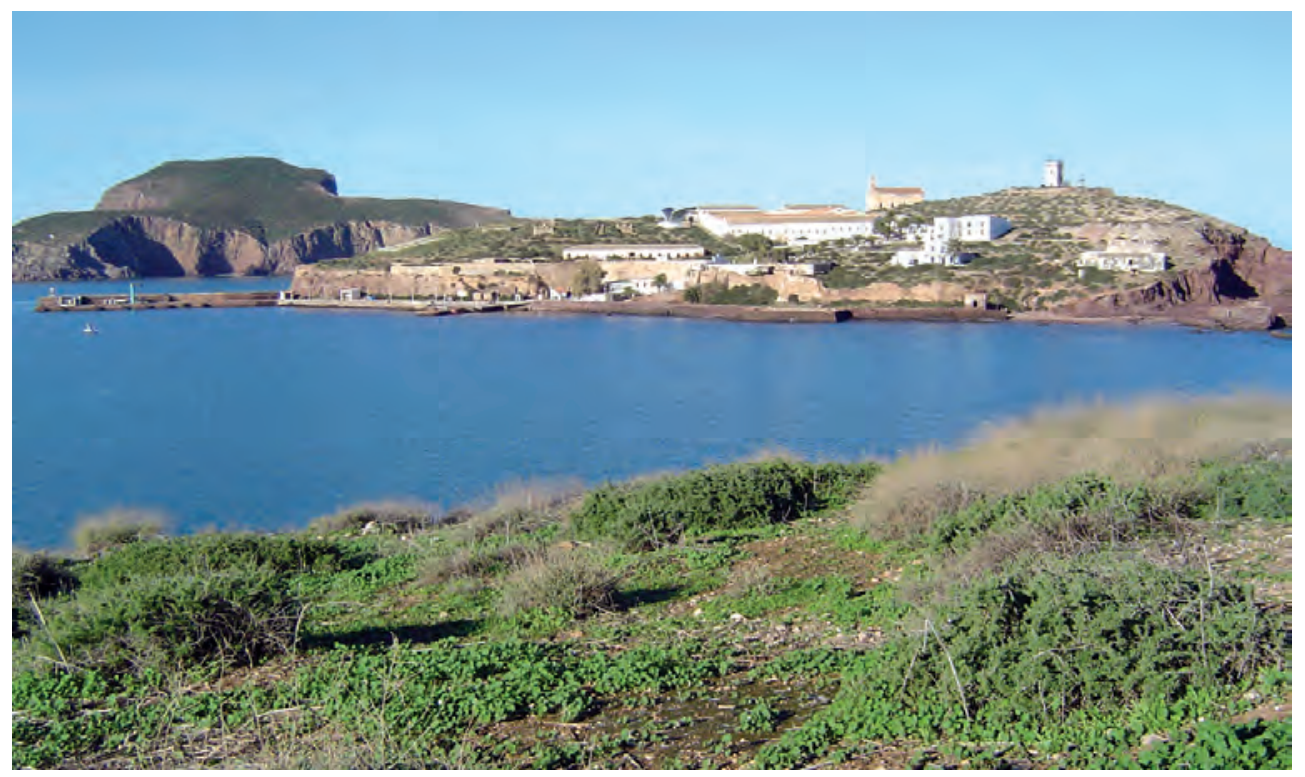

Las islas Chafarinas actualmente, vista desde la isla del Rey.

Con la crisis generada por la ocupación mar roquí del islote de Perejil en julio de 2002, el gobierno vuelve a centrar su atención en las Chafarinas y decide reforzar su guarnición con tropas de Regulares de Melilla ante las maniobras de unas patrulleras marroquíes en las aguas del arc hipiélago. Las tropas ocuparon posiciones en las islas deshabitadas del Cong reso y Rey para evitar sorpresas. Asimismo se enviaron unidades de la Armada para colaborar en la vigilancia del archipiélago ${ }^{37}$. Con la normalización de la situación tras la reconquista del islote Perejil, la guarnición extraordinaria regresó a sus cuarteles de Melilla y Chafarinas volvió a su letargo.

En estos últimos años la Armada comenzó a retirar del servicio a los buques aljibes que abastecían a Chafarinas, Peñón deVélez, Alhucemas y la isla deAlborán. Esto obligó a plantearse el futuro del abastecimiento de agua a las islas y el gobierno optó por la utilización de nueas tecnologías y energías renovables, aprobando a finales del año 2009 la construcción en Chafarinas de un generador de agua sanitaria por condensación y una planta de energía solar fotoroltaica ${ }^{38}$ para asegurar las

\footnotetext{
$37 A B C$ del 13/07/2002.

$38 \mathrm{BOE} \mathrm{n}^{\circ} 289 \operatorname{del} 01 / 12 / 2009 \mathrm{y} \mathrm{n}^{\circ} 294 \operatorname{del} 07 / 12 / 2009$.
} 
necesidades de los hombres y mujeres encargados de mantener nuestra presencia en este entrañable trozo de tierra española de cara a los tiempos venideros.

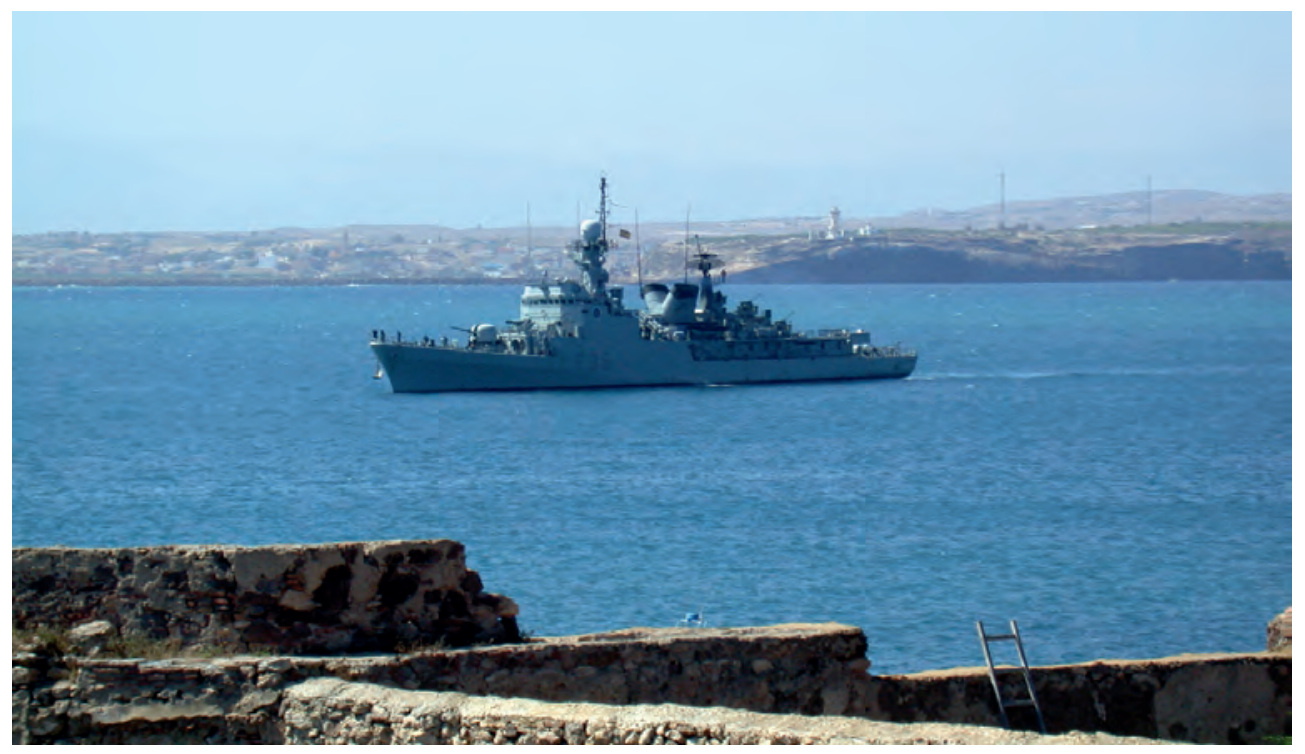

Corbeta Cazadora F35, enviada a las islas Chafarinas cuando se origina el conflicto con Marruecos por la isla de Perejil.

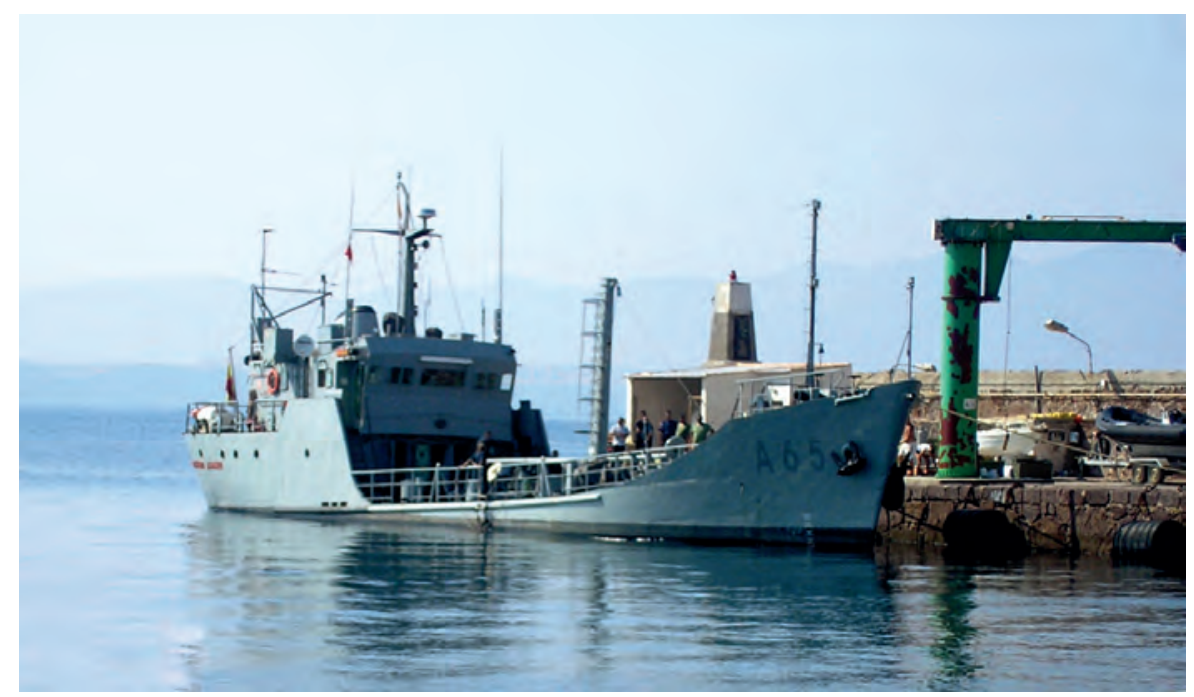

Barco aljibe atracado en el puerto de la isla Isabel II en el año 2005, hoy este servicio ha sido retirado a causa de la instalación de un generador de agua sanitaria por condensación y una planta de energía solar fotovoltaica. 


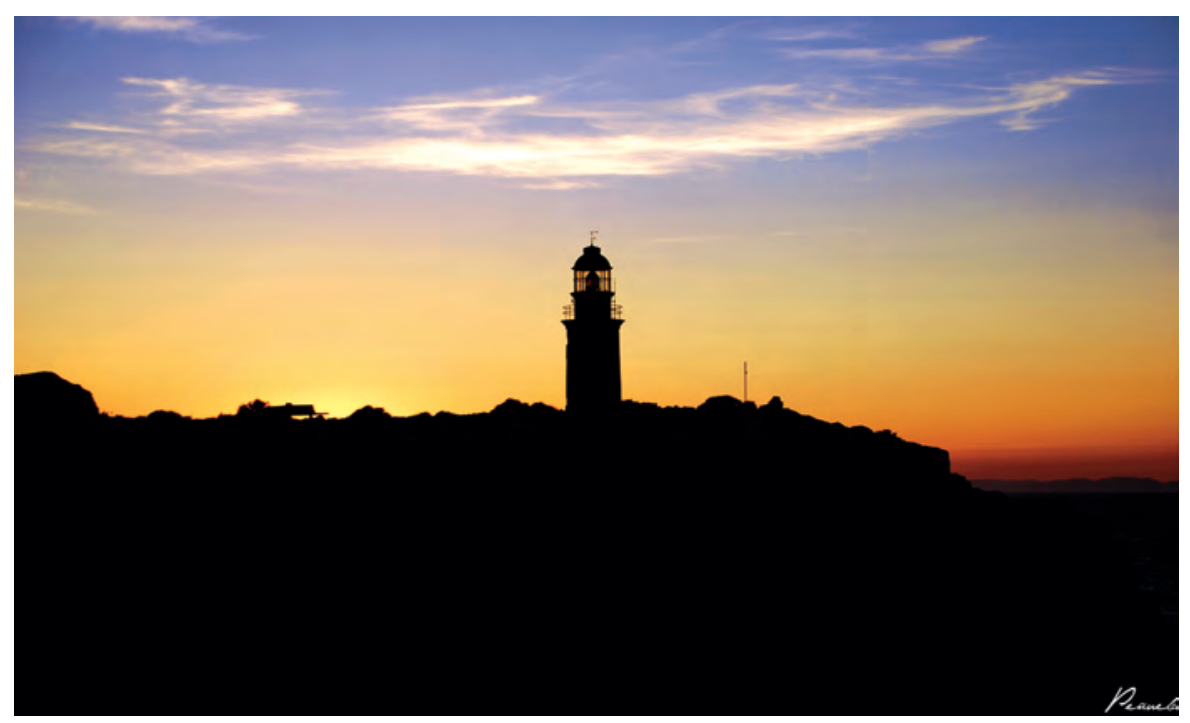

Atardecer sobre el faro, 2009. José María Peñuela.

\section{BIBLIOGRAFIA}

BARCÍA, María del Carmen (2003). Desterrados de la Patria. Cuba 1869 - 1898. La Habana: Universidad, $\mathrm{n}^{\circ} 258\left(2^{\circ}\right.$ semestre $)$.

BECKER, Jerónimo (1915). Historia de Marruecos. Madrid.

DEL REY, Miguel (2001). La Guerra de África. Medusa Ediciones.

ESQUEMBRI HINOJO, Carlos (2006). “Algunos datos sobre el sector pesquer o melillense (1900 1930) I. La Gaceta del Telegrama de Melilla. 09/07/2006.

ESQUEMBRI HINOJO, Carlos (2009). "Las Comunicaciones marítimas de Melilla en 1909. La Gaceta del Telegrama de Melilla. 20/09/2009.

HERRÁN LÓPEZ, Ángel y AVILÉS, Juan (2003). El nacimiento del terrorismo en occidente. Ed. Siglo XXI.

LÓPEZ CORDÓN, María Victoria (1982). "La política exterior en la era isabelina y el Sexenio Democrático”. Historia de España, tomo XXXIV. Madrid: Espasa Calpe.

LÓPEZTIRADO, Jacinto (2002). Islas Chafarinas, un paseo por su historia. Melilla: Ciudad Autónoma.

MOGA ROMERO, Vicente (1988). "Melilla y las Plazas Menor es (Chafarinas, Vélez de la Gomera y Alhucemas) en el Diccionario Geográfico-Estadístico-Histórico de España y sus posesiones de ultramar. (Madrid 1845-1850) Pascual Madoz”. En: Aldaba nº 9. UNED de Melilla.

MORALESY MENDIGUTÍA, Gabriel de (1909). Datos para la historia de Melilla. Melila: Imp. ElTelegrama del Rif.

PASTOR GARRIGUES, Francisco. España y la aper tura de la cuestión mar roquí (1897 - 1904). Tesis doctoral. http: / /hdl.handlenet/10803/9958.

VILLAR, María José (2006). “España, Alemania y las islas Chafarinas en vísperas del replanteamiento de la cuestión marroqui’. Studia histórica. Historia Contemporánea, nº 24; págs. 207 - 229.

VIRUELA MARTÍNEZ, Rafael (1995). "Expansión y crisis de la actividad pesquera valenciana en el siglo XIX”. Investigaciones geográficas nº 13; págs. $117-133$. 